\title{
Stratospheric effects of Mount Pinatubo aerosol studied with a coupled two-dimensional model
}

\author{
Joan E. Rosenfield \\ General Sciences Corporation, Laurel, Maryland \\ David B. Considine and Paul E. Meade \\ Applied Research Corporation, Landover, Maryland \\ Julio T. Bacmeister \\ Naval Research Laboratory, Washington, D. C. \\ Charles H. Jackman and Mark R. Schoeberl \\ NASA Goddard Space Flight Center, Greenbelt, Maryland
}

\begin{abstract}
A new interactive radiative-dynamical-chemical zonally averaged two-dimensional model has been developed at Goddard Space Flight Center. The model includes a linear planetary wave parameterization featuring wave-mean flow interaction and the direct calculation of eddy mixing from planetary wave dissipation. It utilizes family gas phase chemistry approximations and includes heterogeneous chemistry on the surfaces of both stratospheric sulfate aerosols and polar stratospheric clouds. This model has been used to study the effects of the sulfate aerosol cloud formed by the eruption of Mount Pinatubo in June 1991 on stratospheric temperatures, dynamics, and chemistry. Aerosol extinctions and surface area densities were constrained by satellite observations and were used to compute the aerosol effects on radiative heating rates, photolysis rates, and heterogeneous chemistry. The net predicted perturbations to the column ozone amount were low-latitude depletions of $2-3 \%$ and northern and southern high-latitude depletions of $10-12 \%$, in good agreement with observations. In the low latitudes a depletion of roughly $1-2 \%$ was due to the altered circulation (increased upwelling) resulting from the perturbation of the heating rates, with the heterogeneous chemistry and photolysis rate perturbations contributing roughly $0.5 \%$ each. In the high latitudes the computed ozone column depletions were mainly a result of heterogeneous chemistry occurring on the surfaces of the volcanic aerosol. Temperature anomalies predicted were a low-latitude warming peaking at $2.5 \mathrm{~K}$ in mid-1992 and high-latitude coolings of 1-2 $\mathrm{K}$ which were associated with the high-latitude ozone reductions. The sensitivity of the predicted perturbations to changes in the specification of the planetary wave forcings was examined. The maximum globally averaged column ozone depletions ranged from 2 to $4 \%$ for the cases studied.
\end{abstract}

\section{Introduction}

The eruption of Mount Pinatubo $\left(15^{\circ} \mathrm{N}, 120^{\circ} \mathrm{E}\right)$ in the Phillippines injected a large amount of sulfur dioxide into the stratosphere on June 15, 1991. Subsequently, sulfuric acid aerosols were formed from the sulfur dioxide, and they gradually spread over both hemispheres. The global distribution and dispersion of the Pinatubo aerosol has been measured by the Stratospheric Aerosol and Gas Experiment II (SAGE II) [McCormick and Veiga, 1992; Trepte et al., 1993]. For the first several months the aerosol cloud was largely confined to the tropics. It moved into the southern hemisphere midlatitudes by September 1991 and into the northern hemisphere middle and high latitudes during the winter of 1991-1992. It did not enter the southern hemisphere high latitudes until after the breakup of the Antarctic polar vortex in 1991.

Copyright 1997 by the American Geophysical Union.

Paper number 96JD03820.

0148-0227/97/96JD-03820\$09.00
Observations have revealed both chemical and radiative effects following the Mount Pinatubo eruption. For example, Gleason et al. [1993] reported that global average total ozone measured by the total ozone mapping spectrometer (TOMS) on the Nimbus 7 satellite was 2 to $3 \%$ lower than any year since 1979 when the observations started. Hofmann et al. [1993, 1994] reported large reductions in lower stratospheric ozone in 1992-1993 in the United States. There were large reductions in $\mathrm{NO}_{2}$ accompanied by enhancements in $\mathrm{HNO}_{3}$ at Lauder, New Zealand, reported by Koike et al. [1994]. In addition to these and other chemical perturbations reported, Labitzke and $\mathrm{Mc}$ Cormick [1992] and Angell [1993] published results showing increases in tropical stratospheric temperatures after the eruption of Mount Pinatubo.

There have been several published modeling studies of the stratospheric effects of the Mount Pinatubo aerosol. Kinne et al. [1992] used a one-dimensional radiative transfer model with observed particle size distributions to compute a heating rate perturbation in the tropics due to the aerosol of $0.3 \mathrm{~K} / \mathrm{d}$. With a mechanistic model accounting for temperature-aerosol- 
ozone feedbacks and using the observed temperature changes, they computed tropical ozone column losses of $10-30 \%$ due to upwelling, which were larger than observed by Schoeberl et al. [1993]. Young et al. [1994] combined an aerosol microphysical/ transport model with a three-dimensional (3-D) circulation model to compute a temperature perturbation of $1-4 \mathrm{~K}$ due to aerosol heating.

Brasseur and Granier [1992] used a two-dimensional (2-D) chemical-radiative-dynamical model to separately examine the effects of heterogeneous reactions and additional aerosol heating. Their nonvolcanic case included background aerosols and polar stratospheric clouds (PSCs). The specification of an additional tropical heating of $0.4 \mathrm{~K} / \mathrm{d}$ led to temperature increases of 2 to $6 \mathrm{~K}$ and ozone column reductions less than $3 \%$. The heterogeneous chemistry included the hydrolysis of $\mathrm{N}_{2} \mathrm{O}_{5}$ and of $\mathrm{ClONO}_{2}$ on PSC and aerosol particle surfaces. Their chemistry run, using an assumed aerosol surface area density (SAD), gave very small tropical ozone changes but higher northern hemisphere ozone column losses of $10 \%$ in January to March 1992.

Pitari [1993] used a 3-D spectral model together with lidar and satellite aerosol measurements to investigate the dynamical effects of the Mount Pinatubo aerosol. They found a lower stratospheric warming of $\sim 1.5 \mathrm{~K}$ during September and October following the eruption, $1-2 \%$ column ozone decreases in the tropics due to upwelling, and $3-4 \%$ column ozone increases at northern middle and high latitudes due to downwelling. In a further study, Pitari and Rizi [1993] used a 2-D noninteractive model with temperatures and circulation taken from their 3-D model to include the effects of the perturbed heterogeneous conversion of $\mathrm{N}_{2} \mathrm{O}_{5}$ and $\mathrm{ClONO}_{2}$ on the volcanic aerosol. Pitari and Rizi [1993] used surface area densities derived from SAGE II satellite data. They calculated ozone depletions of $12 \%$ in the high northern latitudes due to the heterogeneous chemistry perturbation and $10 \%$ in the tropics due to the combined radiative and heterogeneous chemical perturbations. In the tropics their radiative and chemical depletions were comparable, with the radiative depletion due mostly to photolysis rate changes.

Bekki and Pyle [1994] used a detailed aerosol microphysical model with an interactive chemical-radiative-dynamical 2-D model to study the effect of the volcanic perturbation of the hydrolysis of $\mathrm{N}_{2} \mathrm{O}_{5}$ on aerosol surfaces. They did not include the radiative effect. They predicted ozone column reductions up to $5-7 \%$, with the largest reductions occurring at high latitudes in both hemispheres.

Kinnison et al. [1994] studied the combined chemical and radiative effects of the Mount Pinatubo aerosol perturbation using a chemical-radiative-dynamical 2-D model containing a representation of heterogeneous reactions on PSCs. They included the heterogeneous conversion of $\mathrm{N}_{2} \mathrm{O}_{5}$ and of $\mathrm{ClONO}_{2}$ on sulfate aerosols, using surface area densities derived from data from both SAGE II and the cryogenic limb array etalon spectrometer (CLAES) on the Upper Atmosphere Research Satellite (UARS). The radiative heating anomaly was allowed to modify either the temperatures or the circulation. When the aerosol heating perturbed the temperatures, they calculated an equatorial temperature increase of $6 \mathrm{~K}$ and an equatorial column ozone decrease of $1.5 \%$, while when the aerosol heating perturbed the circulation, they calculated an equatorial column ozone decrease of $6 \%$. The chemical perturbations gave rise to ozone column reductions of $10 \%$ in the southern hemisphere high latitudes and $4 \%$ in the northern hemisphere high latitudes.
Tie et al. [1994] used an interactive 2-D radiative-dynamicalchemical model to study the Mount Pinatubo aerosol perturbation. The temporal and spatial distributions of the aerosol were given by an aerosol microphysical model. They derived a heating rate anomaly of $0.22 \mathrm{~K} / \mathrm{d}$ which gave rise to a maximum temperature increase in the tropics of $4.5 \mathrm{~K}$. They calculated ozone column losses of roughly $2 \%$ in the tropics due mainly to the circulation and photolysis rate changes and up to $12 \%$ in the high northern latitudes due mainly to the heterogeneous conversion of $\mathrm{N}_{2} \mathrm{O}_{5}$ and $\mathrm{ClONO}_{2}$ on the sulfate aerosols. They did not present computed ozone changes for the southern hemisphere since these would be affected by heterogeneous processes occurring on PSCs which were not included in their study.

Of these model studies, the most complete were those of Kinnison et al. [1994] and Tie et al. [1994]. However, the model of Kinnison et al. [1994], which used observed aerosol data, was not totally interactive in that the radiative heating anomaly could perturb the temperatures or the circulation of the model but not both simultaneously. The model of Tie et al. [1994], which predicted the aerosol distributions from a microphysical model, was totally interactive but did not include heterogeneous processing on the surfaces of PSCs.

In this paper we present a new radiative-dynamical-chemical global 2-D (latitude-height) model which is totally interactive and which incorporates heterogeneous chemistry on the surfaces of both sulfate aerosols and polar stratospheric clouds. The model has been used to study the stratospheric perturbations following the eruption of Mount Pinatubo. Aerosol surface area densities needed for the heterogeneous chemistry calculations and aerosol optical depths needed for the heating rate and photolysis rate calculations were constrained by observations.

The description of the radiative, chemical, and dynamical components of the model will be given in section 2 and the results in section 3 , with section 3.1 devoted to the resulting model climatology with the inclusion of the background aerosol and section 3.2 devoted to the modeled changes due to the volcanic aerosol perturbation. Separate runs are discussed in which the volcanic perturbation is included in the heterogeneous chemistry only, the heating rates only, the photolysis rates only, and finally, a run with the perturbation in the chemistry and radiation.

\section{Model Description}

This model couples the Goddard Space Flight Center 2-D fixed transport chemistry model described by Douglass et al. [1989] and Jackman et al. [1990] with the zonally averaged radiative-dynamical model described by Bacmeister et al. [1995]. In this coupled model, the diabatic heating rates computed from the model temperature and ozone fields determine the temperatures and the transport circulation. The temperature dependences of the gas phase chemical reactions are determined using the model-predicted temperatures. The component radiative, chemical, and dynamical modules are described in the following sections.

\subsection{Radiation}

The method for computing the clear sky heating rates is as described by Rosenfield et al. [1994]. It takes into account solar heating due to ozone, water vapor, and carbon dioxide and infrared heating and cooling due to carbon dioxide, ozone, and water vapor. The broadband parameterizations incorporated 
in the model have been derived from or benchmarked against more detailed computations. Temperature and ozone profiles used in the heating rate computation are those predicted by the model, while water vapor amounts used are monthly, zonally averaged profiles from the Nimbus 7 Limb Infrared Monitor of the Stratosphere (LIMS) instrument in the stratosphere combined with a tropospheric climatology. The model surface temperatures are allowed to relax to climatological values. Descent rates in the polar regions computed by the clear sky radiation model compare well with those derived from observations of long-lived trace gases [Bacmeister et al., 1995; Crewell et al., 1995; Schoeberl et al., 1995; Strahan et al., 1994].

Latitudinally dependent effective tropospheric cloud heights and amounts were specified. These were determined by trial and error in such a way that the computed top of the atmosphere outgoing longwave flux agreed with satellite observations. This procedure ensures that the upwelling infrared flux reaching the stratosphere from the troposphere is realistic. This is particularly important to achieve in the window region of the spectrum, where the upwelling flux from the lower atmosphere plays a critical role in determining the sign as well as the magnitude of the infrared heating in the low latitudes. The cloud fields as well as the comparison of the computed outgoing longwave flux with observations will be discussed below.

The 2-D interactive model currently incorporates an explicit heat source to simulate the release of latent heating in the troposphere. Although the parameterization is highly simplified, it is qualitatively consistent with latent heating distributions derived from data [e.g., Newell et al., 1974]. The latent heating in our model, however, is somewhat stronger overall than the derived values, both in the magnitude of the peak heating and in the heating asymmetry between the northern and the southern hemisphere. The larger latent heating values in our model serve primarily to offset the model's tropospheric temperature deficiency, particularly near the tropical and midlatitude tropopause, and to improve the relative magnitudes and seasonal variation of the subtropical tropospheric jets.

The latent heating parameterization consists of a pair of latent heating nodes, one primarily effective in each hemisphere, which have seasonally varying magnitudes. The peak heating for each node occurs at an altitude of $8 \mathrm{~km}$ and a latitude of $10^{\circ}$ into the opposite hemisphere. The magnitude of the heating decreases quadratically in the vertical direction (both upward and downward) over a distance of $8 \mathrm{~km}$. In the polar direction (toward the pole in the hemisphere containing most of the node's heating) the magnitude of the latent heating decreases linearly over a scale of $140^{\circ}$. In the tropical direction the heating magnitude decreases quadratically over a distance of $25^{\circ}$. Each node achieves its maximum heating at summer solstice in the appropriate hemisphere and zero heating at winter solstice. The maximum heating at the peak in the northern hemisphere is $2.25 \mathrm{~K} / \mathrm{d}$, and the southern hemisphere maximum is $4.25 \mathrm{~K} / \mathrm{d}$.

Wavelength dependent aerosol optical depths and singlescattering albedos needed for the heating rate computation were determined from satellite extinction measurements and Mie theory calculations of extinction and absorption cross sections. The data needed for the Mie theory computations are the wavelength dependent complex index of refraction and the particle size. The refractive index data of Palmer and Williams [1975] for a 75\% solution of sulfuric acid were used. At wavelengths shorter than about $2 \mu \mathrm{m}$ sulfuric acid is transparent; hence the absorption spectrum and the solar heating in the near infrared can be dominated by impurities. Following Pollack et al. [1981], we used an imaginary index of refraction of $1.5 \times 10^{-3}$ between 0.7 and $2 \mu \mathrm{m}$ in computing the cross sections in the near infrared. This value was based on absorption measurements by Ogren et al. [1981] and yields a singlescattering albedo of 0.989 .

The other component needed for the Mie calculations is the particle size. Lognormal size distributions which are fits to observations were used in this work. The lognormal distribution is given as

$$
n_{i}(r) d r=\sum N_{\imath}(2 \pi)^{-1 / 2} \exp \left(-\alpha_{\imath}^{2} / 2\right) d \alpha_{i},
$$

where

$$
\alpha_{i}=\ln \left(r / r_{i}\right) / \ln \sigma_{i}
$$

The three parameters specifying the distribution are $N_{l}$, the total number concentration, $r_{l}$, the median radius (sometimes called the mode radius), and $\sigma_{t}$, the distribution width. For the background aerosol we used a unimodal lognormal size distribution with $r_{t}=0.05 \mu \mathrm{m}$ and $\sigma_{t}=2.2$ [Hoffman, 1990]. For the volcanic aerosol the distribution chosen was a bimodal lognormal distribution with $N_{l}$ of 33 and $2 \mathrm{~cm}^{-3}, r_{t}$ of 0.1 and $0.5 \mu \mathrm{m}$, and $\sigma_{\imath}$ of 1.8 and 1.25 , respectively [Deshler, 1992]. This distribution was a fit to balloon measurements made on August 2, 1991. In preliminary calculations we used a variety of observed volcanic size distributions [Deshler et al., 1992, 1993] to determine heating rates in the manner described below. Of this set we chose the distribution which yielded an average heating rate.

While the size distributions for both the background and the volcanic aerosols were kept constant, the spatial and temporal variability of the aerosol was incorporated into the calculations by using spatially and temporally varying aerosol number densities determined from satellite extinction data. We used monthly and zonally averaged SAGE II $1 \mu \mathrm{m}$ stratospheric extinction coefficients. Where the satellite data were missing, we interpolated in space and time in order to obtain a global data set. The values poleward of the highest latitude data points were set equal to the highest-latitude values which existed. Extinction coefficients greater than $0.03 \mathrm{~km}^{-1}$ were assumed to be due to cirrus clouds and were excluded. No aerosol was included in the troposphere. Computed number densities for the volcanic aerosol were determined by dividing the observed $1 \mu \mathrm{m}$ extinction coefficients by a $1 \mu \mathrm{m}$ cross section computed using the above size distribution, normalized to unity. For the pre-Pinatubo aerosol the $1 \mu \mathrm{m}$ extinction coefficients from the work of Hitchman et al. [1994] were used together with a $1 \mu \mathrm{m}$ cross section computed using the background size distribution. The Hitchman climatology was created by combining SAGE I and II and Stratospheric Aerosol Measurement (SAM II) observations from 1979 to 1981 and from 1984 to 1990 and, as noted by Hitchman et al. [1994], is distinctly volcanic in nature. Finally, these spatially and temporally varying number densities were multiplied by the wavelength dependent computed cross sections to yield the absorption and extinction coefficients used in the radiative transfer model.

In the infrared the wavelength dependent single-particle cross sections were averaged over the wide bands of our radiation model as in the work of Rosenfield [1992]. This approximation is justified by the optical thinness of the aerosol in any given model layer, in which case the linear approximation of 
radiative transfer holds. For the near-infrared solar absorption band, from 0.7 to $4 \mu \mathrm{m}$, the cross sections were averaged weighted by the solar flux. If this is not done, the absorption of solar radiation by the aerosol would be overestimated since the solar flux varies with wavelength in a sense opposite to that of the cross section.

The direct radiative effect of PSCs has not been included. This has been estimated to be $\pm 0.1 \mathrm{~K} / \mathrm{d}$ [Rosenfield, 1992], with the net effect being heating over a relatively warm surface and cooling over a relatively cold surface. The direct radiative effect of the PSCs would appear in both the volcanic experiments and in the control run and so, in zeroth order, would tend to cancel in determining the perturbations due to the volcanic aerosol. However, PSC amounts can change in response to volcanically induced changes in constituents which could result in a very small contribution to the volcanic heating rate perturbation.

The photolysis rate computations used 39 wavelength bins, from 1215 to $7300 \mathrm{~nm}$. Optical depths included the extinction due to aerosols, and the aerosol extinction and absorption cross sections at the 39 wavelengths were computed as described above. Gaseous absorption cross sections were taken from DeMore et al. [1987]. The mean intensity, or photolytic source term, was the sum of the attenuated direct beam and the diffuse beam. The attenuation of the direct beam was calculated by using spherical geometry, while the diffuse beam was calculated using multiple scattering with plane parallel geometry only. We used the two-stream Eddington approximation multiple-scattering algorithm described by Toon et al. [1989], together with the delta scalings of Joseph et al. [1976] to treat the anisotropic scattering associated with aerosols. At wavelengths less than $2000 \mathrm{~nm}$, in the Schumann-Runge region of the spectrum, multiple scattering was not included.

\subsection{Chemistry}

The model chemistry is essentially the same family chemistry scheme used in the GSFC 2-D fixed transport model. The model extends from pole to pole with a $10^{\circ}$ resolution and has 46 pressure levels reaching from the ground to $0.0024 \mathrm{mbar}$ (about $90 \mathrm{~km}$ ). The pressure levels are equally spaced in $\log$ pressure with an approximate $2 \mathrm{~km}$ resolution. The model calculates the concentrations of $\mathbf{5 3}$ gas phase species as well as the total concentrations of the $\mathrm{O}_{x}, \mathrm{NO}_{x}, \mathrm{ClO}_{x}$, and $\mathrm{BrO}_{x}$ families. It transports 28 gas phase species, including $\mathrm{O}_{x}, \mathrm{HO}_{x}$, $\mathrm{NO}_{x}, \mathrm{ClO}_{x}$, and $\mathrm{BrO}_{x}$, obtaining values for the balance of the constituents using photochemical equilibrium assumptions. There are 98 gas phase chemical reactions considered in the chemistry formulation. The concentration of water vapor is calculated below $60 \mathrm{~km}$ and set to a constant $6 \mathrm{ppmv}$ above this level. This results in fairly realistic concentrations of water vapor in the stratosphere and troposphere. In all of the computations described in this paper, the boundary values for the various constituents were set to the 1990 values described in World Meteorological Organization (WMO) [1991].

Heterogeneous reactions on the surfaces of sulfate aerosol particles as well as type 1 and type 2 PSCs were included in the model calculation. Stratospheric sulfate aerosol surface area densities (SADs) were determined from observations in the following way. The spatial and temporally varying aerosol number densities were determined from SAGE II satellite extinction measurements, as described above. These were then multiplied by the area of one particle averaged over the particle size distributions given above to yield surface area densi- ties. No aerosols were included in the troposphere. The PSC surface area densities were calculated as described by Considine et al. [1994]. The surface area densities were obtained from calculated volumes of condensed $\mathrm{HNO}_{3} \cdot 3 \mathrm{H}_{2} \mathrm{O}$ and $\mathrm{H}_{2} \mathrm{O}$ assuming that the aerosol size distributions are lognormal, with mean log radii of 1 and $10 \mu \mathrm{m}$ for type 1 and 2 PSCs, respectively. A supersaturation correction of $3 \mathrm{~K}$ for type 1 PSCs and $2 \mathrm{~K}$ for type 2 PSCs was required before PSC formation occurs. Sedimentation of the PSCs was accounted for, with the entire type 1 or type 2 condensed volume at a particular grid box having the falling speed of the mean log radius.

An important feature of this method is that it avoids using the model-calculated zonal mean temperatures. There are two strong reasons for doing this. First, the temperatures calculated by the model at high latitudes in the lower stratosphere during the wintertime are approximately $10^{\circ} \mathrm{K}$ colder than climatological values, as discussed in more detail below. This is consistent with other 2-D models that use a planetary wave parameterization and the model $\mathrm{O}_{3}$ distribution to calculate the model residual circulation [e.g., Tie et al., 1994]. Using the model temperatures would result in an overestimate of PSC formation. Second, as discussed by Considine et al. [1994], the zonal mean temperature is not a good predictor of PSC formation. Because of longitudinal temperature variability, PSCs will often form in regions where the zonal mean temperature is above the threshold for PSC formation. For these two reasons, the method we use is based on probability distributions that describe the longitudinal temperature variability as a function of time of year and location. The condensed volume of type 1 and type 2 PSCs are calculated by using integrals over the probability distributions, thus taking longitudinal variations in temperature into account. The probability distributions were obtained from 15 years (1979-1993) of National Meteorological Center (NMC) temperature data. By using the probability distributions a more realistic description of PSC behavior is obtained. However, a consequence is that the calculated PSC surface area densities will not respond to any changes that may occur to the model temperature field as a result of the volcanic eruption.

Five heterogeneous reactions occur on the surfaces of the sulfate aerosol and polar stratospheric clouds. They are

$$
\begin{gathered}
\mathrm{N}_{2} \mathrm{O}_{5}+\mathrm{H}_{2} \mathrm{O} \rightarrow 2 \mathrm{HNO}_{3} \\
\mathrm{~N}_{2} \mathrm{O}_{5}+\mathrm{HCl} \rightarrow \mathrm{ClONO}+\mathrm{HNO}_{3} \\
\mathrm{ClONO}_{2}+\mathrm{HCl} \rightarrow \mathrm{Cl}_{2}+\mathrm{HNO}_{3} \\
\mathrm{ClONO}_{2}+\mathrm{H}_{2} \mathrm{O} \rightarrow \mathrm{HOCl}+\mathrm{HNO}_{3} \\
\mathrm{HOCl}+\mathrm{HCl} \rightarrow \mathrm{Cl}_{2}+\mathrm{H}_{2} \mathrm{O}
\end{gathered}
$$

Sticking coefficients describing the reactions of $\mathrm{ClONO}_{2}$ and $\mathrm{HOCl}$ on sulfate aerosols were treated as by Hanson and Ravishankara [1994]. The temperature dependencies of these reactions were calculated using the temperature probability distributions. Sticking coefficients for the other reactions and surfaces were taken from DeMore et al. [1994]. An adjustment to account for the local relative humidity was made to the sticking coefficients for reactions (3), (4), and (5) on type 1 PSCs, as suggested by Tabazadeh and Turco [1993] and Hanson and Ravishankara [1993].

\subsection{Dynamics}

The transport algorithm, which is fully described by Bacmeister et al. [1995], is a highly accurate, momentum- 
Table 1. Test Runs With Various Southern Hemisphere Planetary Wave Forcing Parameters

\begin{tabular}{|c|c|c|c|c|c|}
\hline \multirow[b]{3}{*}{ Case } & \multicolumn{3}{|c|}{ Forcing Parameters } & \multirow{2}{*}{\multicolumn{2}{|c|}{$\begin{array}{c}\mathrm{O}_{3} \text { Column (DU), } \\
\text { at } 85^{\circ} \mathrm{S}\end{array}$}} \\
\hline & \multicolumn{2}{|c|}{ Amplitude Factor ${ }^{\mathbf{a}}$} & \multirow[b]{2}{*}{ Cutoff Latitude } & & \\
\hline & Wave 1 & Wave 2 & & October & January \\
\hline Baseline & 0.125 & 1.50 & $60^{\circ} \mathrm{S}$ and $80^{\circ} \mathrm{S}^{b}$ & 180 & 240 \\
\hline Test A & 0.125 & 0 & $80^{\circ} \mathrm{S}$ & 160 & 200 \\
\hline Test $B$ & 0.125 & 0 & $60^{\circ} \mathrm{S}$ and $80^{\circ} \mathrm{S}^{\mathrm{b}}$ & 80 & 120 \\
\hline Test $\mathrm{C}$ & 0.125 & 1.50 & $60^{\circ} \mathrm{S}$ & 160 & 180 \\
\hline Test D & 0.125 & 0 & $60^{\circ} \mathrm{S}$ & 140 & 140 \\
\hline Test E & 0.500 & 0 & $60^{\circ} \mathrm{S}$ and $80^{\circ} \mathrm{S}^{b}$ & 180 & 200 \\
\hline Test $\mathrm{F}$ & 0.125 & 1.50 & $80^{\circ} \mathrm{S}$ & $300^{\mathrm{c}}$ & 260 \\
\hline
\end{tabular}

conserving advection scheme based on that of Prather [1986]. It is used for the advection of both chemical constituents and dynamical properties. This approach has the advantage that it produces negligible numerical dispersion and diffusion. The dynamical component of the interactive model has a latitudinal extent from $85.1^{\circ} \mathrm{S}$ to $85.1^{\circ} \mathrm{N}$, with a resolution of $4.86^{\circ}$, and a vertical extent from $2.66 \mathrm{~km}$ to $106.4 \mathrm{~km}$, at a resolution of $2.66 \mathrm{~km}$.

Unlike fixed-transport formulations where the circulation is determined from climatological data, the circulation in the current model is driven by the net diabatic heating calculated using the modeled distributions of temperature and ozone. The model incorporates a self-consistent planetary wave parameterization similar to that of Garcia [1991], which calculates the wave-mean flow momentum transfer and estimates the meridional eddy diffusivity produced by wave dissipation. In this formulation, described by Bacmeister et al. [1995], the mechanical forcing of the zonal mean wind includes contributions due to Rayleigh friction, gravity wave drag, vertical momentum diffusion, and momentum deposition from nonlinear breaking of planetary waves. Meridional eddy diffusivity is calculated from the Eliassen-Palm flux divergence of breaking gravity waves using the formula of Newman et al. [1988] for the equivalent diffusivity for quasi-geostrophic potential vorticity. As in the work of Bacmeister et al. [1995], mixing of constituents is assumed to result from both wave breaking and the background dissipation of planetary waves. Background dissipation processes consist of Rayleigh friction and Newtonian cooling. In each case, the damping timescale is set to 100 days below $20 \mathrm{~km}$ and decreases linearly above this altitude to a minimum of 1 day at $220 \mathrm{~km}$, well above the model domain.

The dynamical formulation forces planetary waves from below using a specified surface-level streamfunction perturbation. Bacmeister et al. [1995] used an idealized surface-level stream function. The current model, however, simulates topographic forcing of planetary waves by setting the surface-level perturbation for each mode proportional to the corresponding term of a Fourier decomposition of the Earth's topography at the same latitude, so that

$$
\operatorname{Re}\left\{\Psi_{m}^{\prime}(\phi)\right\}=\alpha_{m}\left\{A_{m}(\phi) \cos (m \lambda)+B_{m}(\phi) \sin (m \lambda)\right\}
$$

where $\Psi_{m}^{\prime}(\phi)$ is the complex surface-level perturbation streamfunction at latitude $\phi$ for a wave with zonal wavenumber $m$, and $A_{m}(\phi)$ and $B_{m}(\phi)$ are the coefficients of the $m$ th order sine and cosine terms in a Fourier series for the topo- graphic relief at latitude $\phi$ as a function of longitude $\lambda$. The constants $\alpha_{m}$ are wave amplitude factors which, in principle, represent the efficiency of topographic forcing of planetary waves and compensate for the simplified representation of the total planetary wave activity in terms of topographically forced stationary waves. If the wave amplitude factor is unity, the surface-level planetary wave stream function perturbation for a given wave mode is identical to the equivalent Fourier term of the topography. In practice, the wave amplitude factors are adjusted for each wave mode and each hemisphere in order to produce reasonable seasonal variations of the zonal winds and distribution of column $\mathrm{O}_{3}$. In the current study, only the lowest two planetary wave modes ( $m=1$ and $m=2$ ) are used in the southern hemisphere. The wave amplitude factors used in the control run are shown in Table 1 . In the northern hemisphere only wave mode 1 is used, with an amplitude of 0.250 .

In this scheme the topography at high latitudes (poleward of $60^{\circ}$ ) produces anomalously high wave amplitudes which dissipate rapidly and result in excessive meridional diffusion coefficients. We address this difficulty by zeroing the Fourier terms for the topography at all model latitudes poleward of $60^{\circ}$ in both hemispheres, except for the period between November 1 and April 30. During this period the topographic forcing is retained to a latitude of $80^{\circ}$ in order to obtain a realistic looking break up of the southern hemisphere polar vortex.

\section{Results}

\subsection{Model Climatology With Background Aerosol}

In the control run the model was run for 10 years with the zonally and monthly averaged background aerosol described above. During the first few years of the run the model converges to an approximate annually repeating steady state condition. Zonal mean temperatures and winds from the seventh year of the control run (nominally the year 1990) are shown in Figure 1 for January and Figure 2 for July. The modeled stratospheric temperatures are in rough agreement with climatological temperatures [Randel, 1992]. At the polar stratopause, wintertime temperatures of $\sim 250 \mathrm{~K}$ and summertime temperatures of $\sim 280 \mathrm{~K}$ are in good agreement with observations. The main deficiencies are a tropical tropopause which is too cold by $5-10 \mathrm{~K}$ and high-latitude lower stratospheric temperatures which are too cold by at least $10 \mathrm{~K}$.

The zonal mean winds (Figures $1 \mathrm{~b}$ and $2 \mathrm{~b}$ ) exhibit the main 

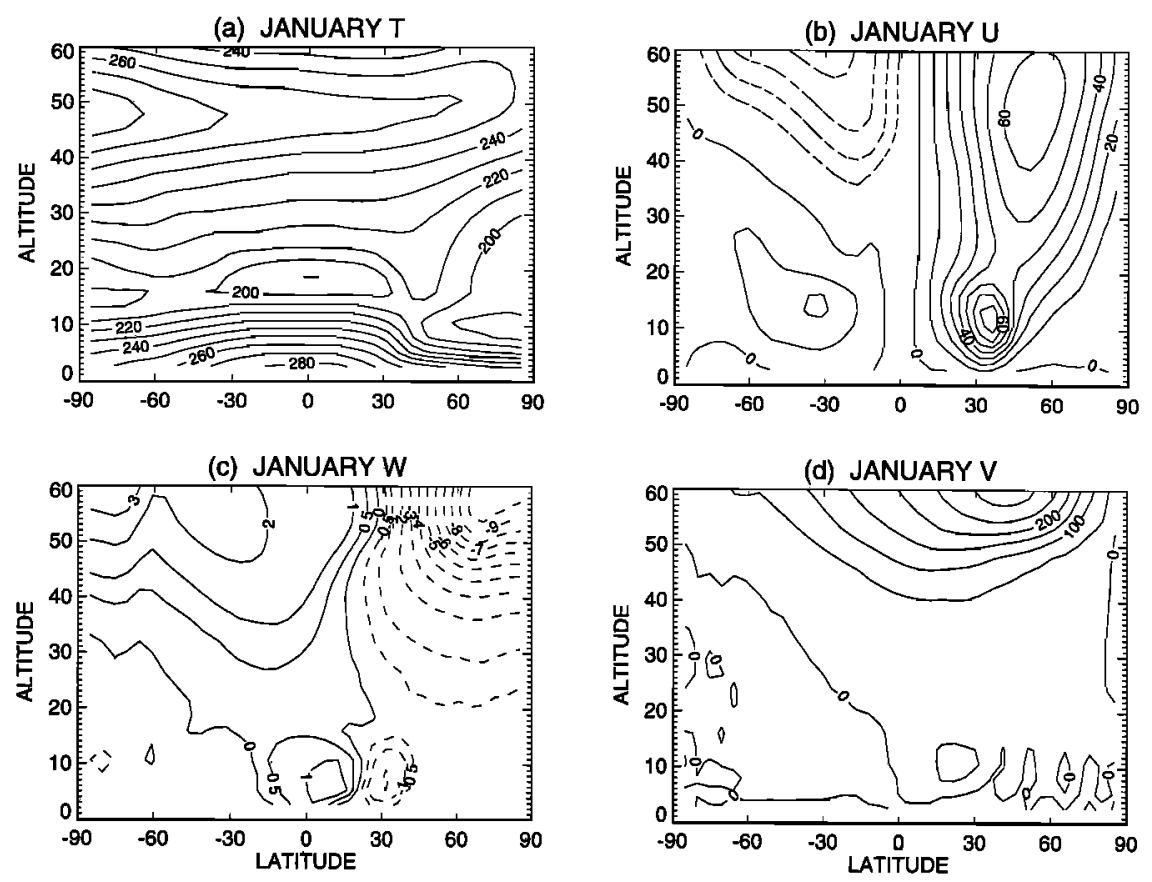

Figure 1. Control run dynamical fields in January: (a) temperature in $\mathrm{K}$, (b) zonal mean wind in $\mathrm{m} / \mathrm{s}$, (c) vertical velocity in $\mathrm{mm} / \mathrm{s}$, (d) meridional velocity in $\mathrm{cm} / \mathrm{s}$. Dashed contours denote negative values.

features shown by observations, namely, westerly subtropical tropospheric jets and stratospheric jets which have a westerly phase in winter and an easterly phase in summer. The maximum velocities of the tropospheric subtropical jet agree quite well with observations [Randel, 1992] for the summer hemisphere, $20 \mathrm{~m} / \mathrm{s}$ in the January southern hemisphere and $10 \mathrm{~m} / \mathrm{s}$ in the July northern hemisphere, compared with the observed values of 25 and $15 \mathrm{~m} / \mathrm{s}$, respectively. The computed values of the winter tropospheric jet, however, are higher than observed, $70 \mathrm{~m} / \mathrm{s}$ in the January northern hemisphere versus the observed
$40 \mathrm{~m} / \mathrm{s}$, and $50 \mathrm{~m} / \mathrm{s}$ in the July summer hemisphere versus the observed $35 \mathrm{~m} / \mathrm{s}$. The computed maximum velocities in the stratospheric winter polar jets are $60 \mathrm{~m} / \mathrm{s}$ in both hemispheres. Observations show that the stratospheric winter jet has much larger maximum velocities in the southern hemisphere than in the northern hemisphere, $90 \mathrm{~m} / \mathrm{s}$ versus $40 \mathrm{~m} / \mathrm{s}$, respectively. The stratospheric easterlies computed by the model have maximum velocities of $40 \mathrm{~m} / \mathrm{s}$ for both the January southern hemisphere and the July northern hemisphere. In comparison, the observed maxima are $50 \mathrm{~m} / \mathrm{s}$ for the January southern hemi- (a) JULY T

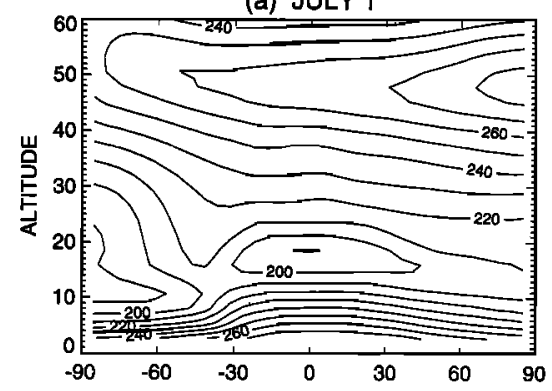

(c) JULY W

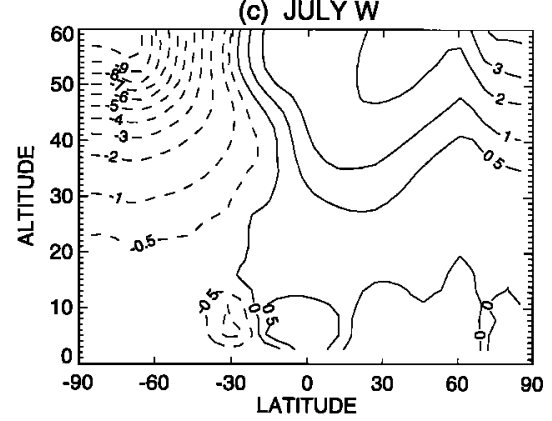

(b) JULY U

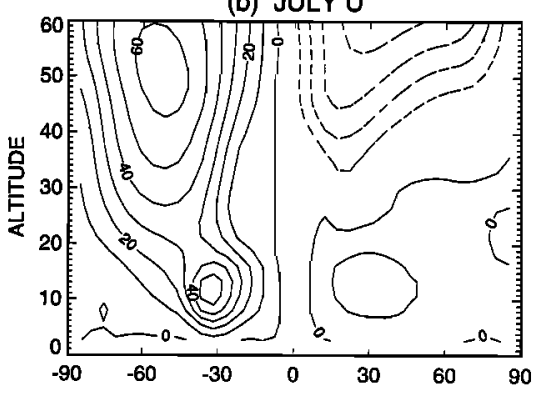

(d) JULYV

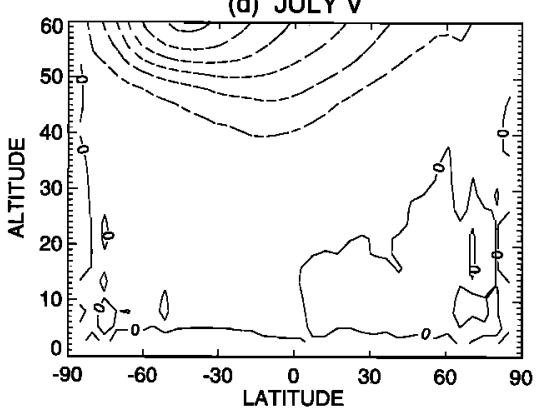

Figure 2. Same as Figure 1 except for July. 

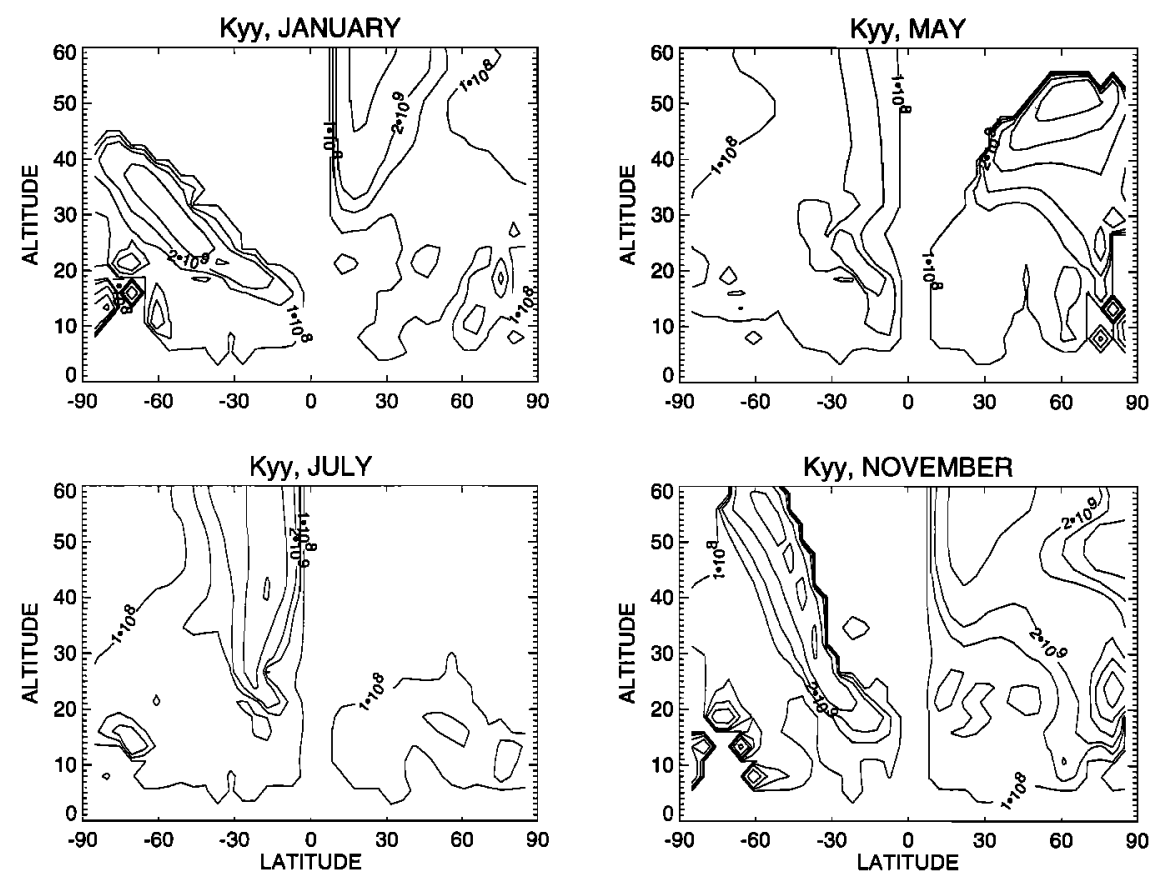

Figure 3. Kyy values, contour intervals of $1 \times 10^{8}, 1 \times 10^{9}, 2 \times 10^{9}, 5 \times 10^{9}, 1 \times 10^{10}$, and $2 \times 10^{10} \mathrm{~cm}^{2} / \mathrm{s}$.

sphere and $30 \mathrm{~m} / \mathrm{s}$ for the July northern hemisphere. The location of the zero wind line dividing the summer hemisphere stratospheric easterlies from the tropospheric westerlies is significantly different from observations. This dividing point occurs at $\sim 20 \mathrm{~km}$ in the observations, while in the model result, it is at $25-45 \mathrm{~km}$ in January and $25-30 \mathrm{~km}$ in July. This is related to a vortex breakdown problem discussed below.

Vertical and meridional velocities are shown in Figures 1 and 2, for January and July, respectively. The residual circulation is characterized by wintertime descent and summertime ascent in the extratropics and continuous vertical ascent in the tropics. In the middle to upper stratosphere the meridional velocity is poleward from the summer to the winter hemisphere, while in the lower stratosphere, there is equator to pole motion. The model-computed residual circulation is similar to diabatic circulations computed from observational data [Rosenfield et al., 1987].

Figure 3 shows the horizontal eddy diffusion coefficients $\left(K_{y y}\right)$ associated with the planetary wave dissipation for January, May, July, and November. In the winter hemispheres the January northern hemisphere and the July southern hemisphere, values of $K_{y y}$ greater than $2 \times 10^{9} \mathrm{~cm}^{2} / \mathrm{s}$ exist only equatorward of the polar night jet, an indication of the isolation of the vortex. There are very low values of $K_{y y}$ in the southern high latitudes from May, when the vortex starts building up, to October. In November, one can see larger values of $K_{y y}$ extending to the south pole as the vortex begins breaking up. In January there is continued mixing of air between the southern hemisphere high and the middle latitudes.

Figure 4 shows the global distributions of the tropospheric source gas methane, which is a good tracer of stratospheric transport. Shown are the model computed methane in parts per million and its ratio to that measured by the CLAES instrument on UARS, for January and July. The modeled fields show maxima in the tropics and minima in the polar latitudes, with steep gradients between the middle and the high latitudes, in agreement with observations [Kumer et al., 1993;
Roche et al., 1996]. The tropical upwelling and the winter high-latitude downwelling are responsible for the characteristic maxima and minima. Throughout most of the lower and middle stratosphere, the modeled methane mixing ratios are within $20 \%$ of the measurements. In the upper stratosphere and mesosphere the computed methane values in the low latitudes are higher than observations, indicating too much upwelling, while in the high latitudes they are significantly lower than observations, indicating too much downwelling. The model $\mathrm{CH}_{4}$ does not show the relatively weak meridional gradients between the subtropics and the middle latitudes, indicative of the midlatitude "surf zone," which are evident in the winter hemisphere observations. This suggests that the Kyy's are not large enough at midlatitudes. Bacmeister et al. [1995] have examined the transport of a passive tracer using essentially the same radiative and dynamical model as this, with a somewhat different choice of planetary wave parameters, as discussed above. They showed that their simulations yielded reasonable reproductions of springtime UARS Halogen Limb Occultation Experiment (HALOE) tracer observations, including the strong wintertime descent within the south polar vortex which brings mesospheric values of $\mathrm{CH}_{4}$ down to $30 \mathrm{mbar}$.

Computed column ozone amounts from the control run are compared with a 1988-1992 average of version 7 TOMS data in Figure 5. The overall agreement of the model with the observations is quite good. Both the magnitude and the location of the northern hemisphere maximum agree well with the observations, and the northern hemisphere 320 Dobson Unit (DU) contour at about day 240 is calculated correctly. The latitudinal gradient between the middle and the low northern hemisphere latitudes is too strong. The tropical values are biased low by $10-20$ DU but are well within $10 \%$ of the observations. In the southern hemisphere high latitudes the springtime maximum is off the pole at $60^{\circ} \mathrm{S}$ in agreement with the data, although it appears a little earlier than observed and is about $20 \mathrm{DU}$ larger than the observed value of $360 \mathrm{DU}$. The minimum ozone value in the computed ozone hole is $180 \mathrm{DU}$, 

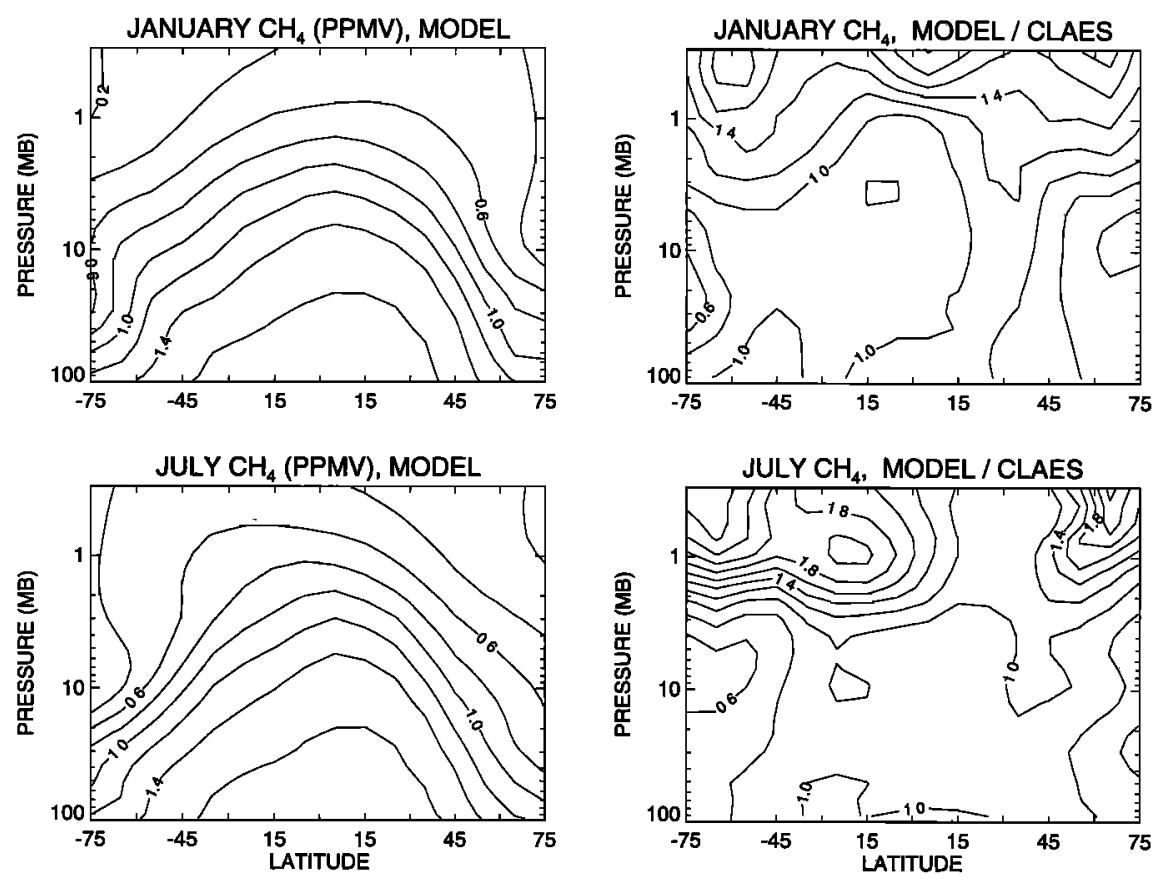

Figure 4. Model $\mathrm{CH}_{4}$ compared with cryogenic limb array etalon spectrometer (CLAES) $\mathrm{CH}_{4}$. The CLAES data were a climatology constructed from observations covering the period January 1992 to May 1993.

in good agreement with the data. It occurs in the model about two weeks later than in the data, where it appears in early October. In the observations the ozone hole breaks up during November, and by January, ozone values of 300-320 occur in the high latitudes. Our model has some difficulty in simulating the breakup of the southern hemisphere polar vortex, so that even by January, ozone column amounts of only 240-270 DU are calculated.

Six additional computations were made in order to test the effect of varying the southern hemisphere forcing parameters used in the planetary wave parameterization. These tests involved various combinations of the wave amplitude factors for wave mode 1 ( 0.125 and 0.50$)$, the wave amplitude factor for wave mode 2 ( 0 and 1.50 ), and the zeroing latitude for waveforcing topography $\left(60^{\circ} \mathrm{S}\right.$ and $80^{\circ} \mathrm{S}$, with and without seasonal variability). As summarized in Table 1, these tests resulted in southern hemisphere ozone hole minimum column $\mathrm{O}_{3}$ abundances ranging between 80 and $180 \mathrm{DU}$, with column $\mathrm{O}_{3}$ abundances in January between 120 and 240 DU. These large variations of the minimum column ozone were a result of changes in the residual circulation and the eddy diffusivity in the southern hemisphere high latitudes. Although temperature changes also occurred, PSC surface area densities did not respond to these changes. As discussed in section 2.2, PSC condensation was determined from temperature probability distributions obtained from observed temperature data. The set of dynamical parameters described for the baseline case produced the best overall agreement of the computed column ozone abundances with observations.

Ozone vertical mixing ratio profiles in parts per million by volume from the control run are shown in Figure 6. Figure 6a shows the profiles computed for October, and Figure $6 \mathrm{c}$ shows the ratio of these profiles to the 1979-1993 average profiles measured by the solar backscattered ultraviolet (SBUV) instrument. The southern hemisphere ozone hole is evident in Figure 6a. In the tropics the agreement with SBUV observa- tions is better than $10 \%$. Elsewhere, the agreement with observations is generally better than $20 \%$, except for the upper stratosphere high latitudes, where the modeled ozone is low. This low ozone is the result of too strong a descent bringing low mesospheric values of ozone down to the stratosphere. The low ozone at $3 \mathrm{mbar}(\sim 40 \mathrm{~km})$ compared to observations is characteristic of two-dimensional models [Prather and Remsberg, 1993]. A tropical and a high-latitude ozone profile are compared with ozonesondes in Figures $6 \mathrm{~b}$ and $6 \mathrm{~d}$. The November $5^{\circ} \mathrm{S}$ profile agrees very well with the November 1990 Brazzaville, Congo ( $\left.4^{\circ} \mathrm{S}\right)$, data, while the October $75^{\circ} \mathrm{N}$ profile
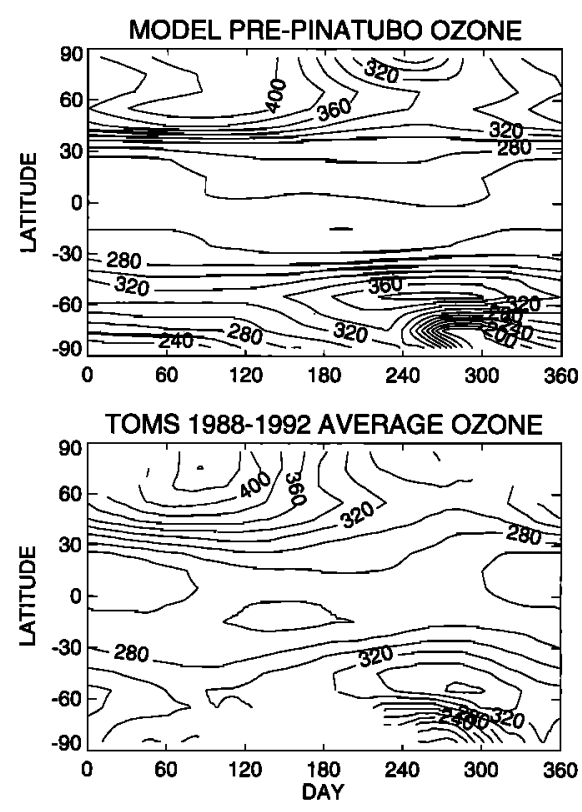

Figure 5. Column ozone (in Dobson units) for control run compared with total ozone mapping spectrometer (TOMS). 
(a) OCTOBER $\mathrm{O}_{3}$ (PPMV), MODEL

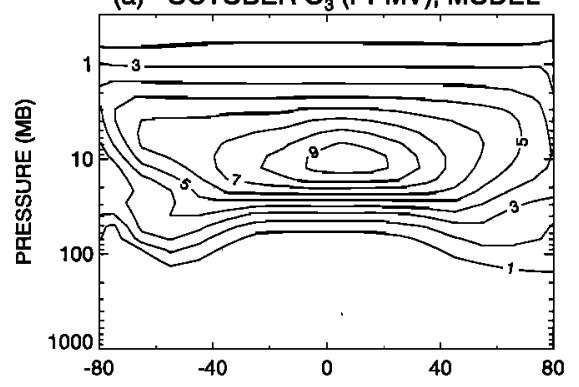

(c) OCTOBER $\mathrm{O}_{3}$ MODEL / SBUV

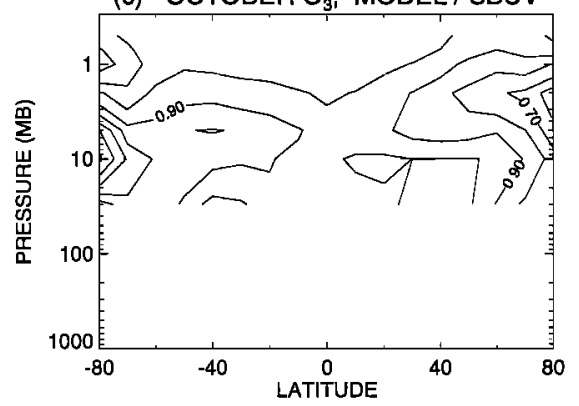

(b) NOVEMBER $\mathrm{O}_{3}, 5^{\circ} \mathrm{S}$

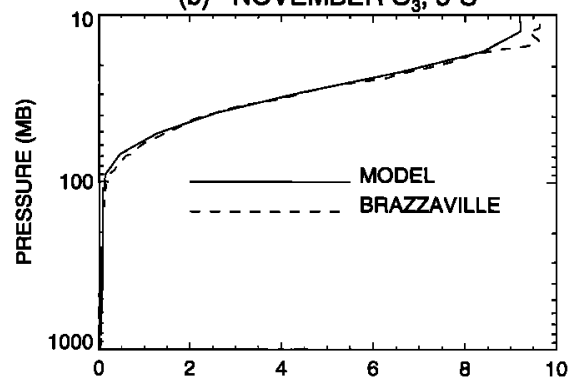

(d) OCTOBER OZONE, $75^{\circ} \mathrm{N}$

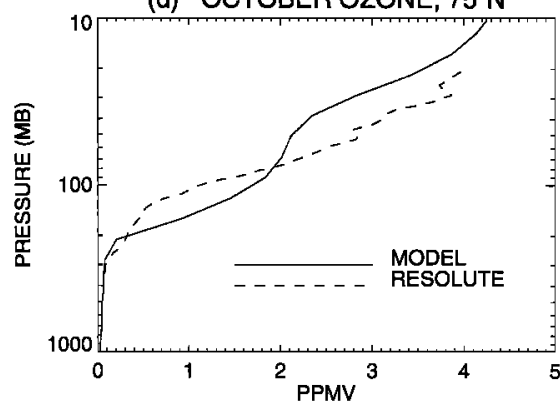

Figure 6. Ozone profiles (in ppmv) for control run compared to observations. (a) October model; (b) November model $\left(5^{\circ} \mathrm{S}\right)$ and November 1990 ozonesondes at Brazzaville (4 $\left.{ }^{\circ} \mathrm{S}\right)$ (average of two soundings); (c) ratio of model to SBUV ozone for October; (d) October model $\left(75^{\circ} \mathrm{N}\right)$, and October 1991 ozonesondes at Resolute $\left(75^{\circ} \mathrm{N}\right)$ (average of four soundings).

is too high relative to the October 1991, Resolute, Canada $\left(75^{\circ} \mathrm{N}\right)$, profile below $80 \mathrm{mbar}$ and too low above.

\subsection{Volcanic Perturbation Results}

Chemistry perturbation. We first discuss an experiment in which the volcanic perturbation was only included explicitly in the heterogeneous chemistry calculation. Changes to the heating and photolysis rates in this run therefore result only from the effects of the perturbed heterogeneous chemistry on the modeled distribution of ozone and other species. The model was run for 10 years in this experiment. The first seven of these years were to allow the model to converge to an annually repeating steady state condition consistent with the model boundary conditions and background levels of sulfate aerosols. In June of the eighth year the sulfate SAD distribution was then set to values derived from SAGE II extinction measurements obtained during June 1991. During the rest of the simulation the SAD distribution was changed monthly to follow the evolution of the sulfate SAD derived from the SAGE II satellite observations as described above.

The aerosol SAD fields for various months used in the model run are shown in Figure 7. The six panels in this figure show zonal mean plots depicting the evolution of the SAD from July 1991 to July 1993 . The panels show that in the first months after the eruption, large SAD values were confined to the tropics, with peak values of just over $25 \mu \mathrm{m}^{2} / \mathrm{cm}^{3}$ at an altitude of about $23 \mathrm{~km}$. Peak SAD values increased over subsequent months to a maximum of about $40 \mu \mathrm{m}^{2} / \mathrm{cm}^{3}$, with the altitude of the peak rising to about $26 \mathrm{~km}$. Significant transport of aerosol out of the tropics first occurred into the southern hemisphere, but order-of-magnitude increases in northern hemisphere high-latitude $\mathrm{SAD}$ do occur in time for the 1991-1992 northern hemisphere winter. By July 1992 the equatorial peak SAD has broadened significantly in latitude, while the altitude has dropped to about $22 \mathrm{~km}$. In the 15 to 20 $\mathrm{km}$ region at this time there are larger $\mathrm{SAD}$ values at high latitudes than at equatorial latitudes, resulting from the poleward and downward circulation characteristic of the stratosphere at these altitudes. By July of 1993, tropical peak values have dropped in magnitude to about $10 \mu \mathrm{m}^{2} / \mathrm{cm}^{3}$, located at about $19 \mathrm{~km}$. At high latitudes, values of up to $15 \mu \mathrm{m}^{2} / \mathrm{cm}^{3}$ are observed near $15 \mathrm{~km}$ during this time. By the time the model integration ends at the end of 1993, typical SAD values have still not returned to the background levels observed before the eruption occurred.

Percent changes in column $\mathrm{O}_{3}$ relative to a control run with background aerosol values are shown in Figure 8. Although small $\mathrm{O}_{3}$ losses of $0.5 \%$ are seen in the tropics in the months immediately following the eruption, the largest effect of the volcanic perturbations on the heterogeneous chemistry occurs at high latitudes in the spring. In the northern hemisphere spring 1992, column $\mathrm{O}_{3}$ decreases in the high latitudes reach a maximum of about $12 \%$ at $65^{\circ} \mathrm{N}$. During spring 1993 at the same location, the magnitude of the $\mathrm{O}_{3}$ decreases are about $20 \%$ smaller than in 1992 due to falling aerosol values. $R o-$ driguez et al. [1994], using a two-dimensional model with the inclusion of heterogeneous chemistry on aerosol surfaces, compute somewhat larger high northern latitude ozone reductions in 1993 than in 1992, which they attribute to the long time constants for ozone in the lower stratosphere.

In the southern hemisphere middle and high latitudes, we compute negligible changes in column $\mathrm{O}_{3}$ during the spring of 1991; however, during spring 1992, column $\mathrm{O}_{3}$ reductions of about $24 \%$ occur, with the maximum reductions in September and October at $65^{\circ} \mathrm{S}$. In the southern hemisphere spring of 1993 the reductions are more moderate, with maximum reductions of about $16 \%$. The response of column ozone in the 

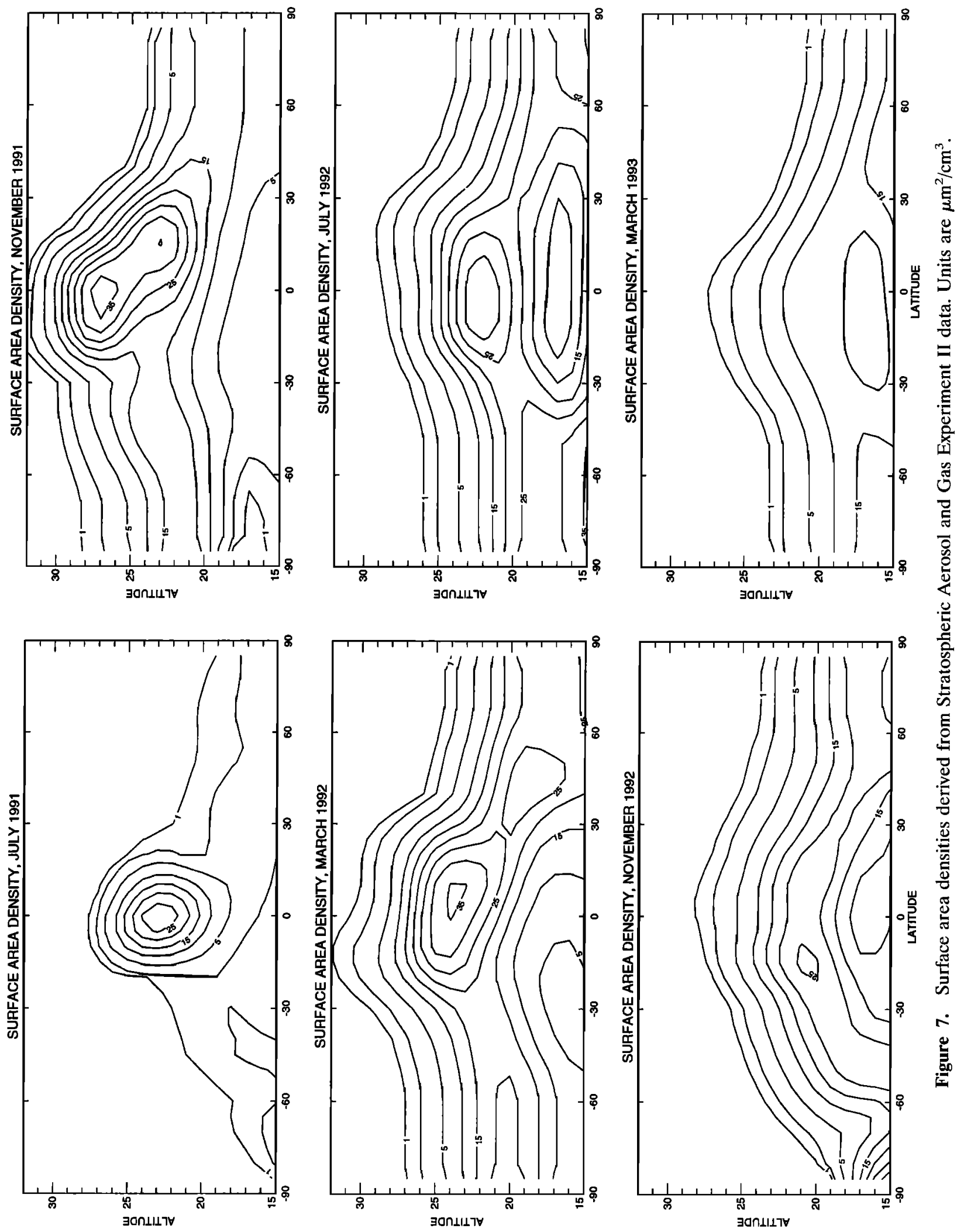


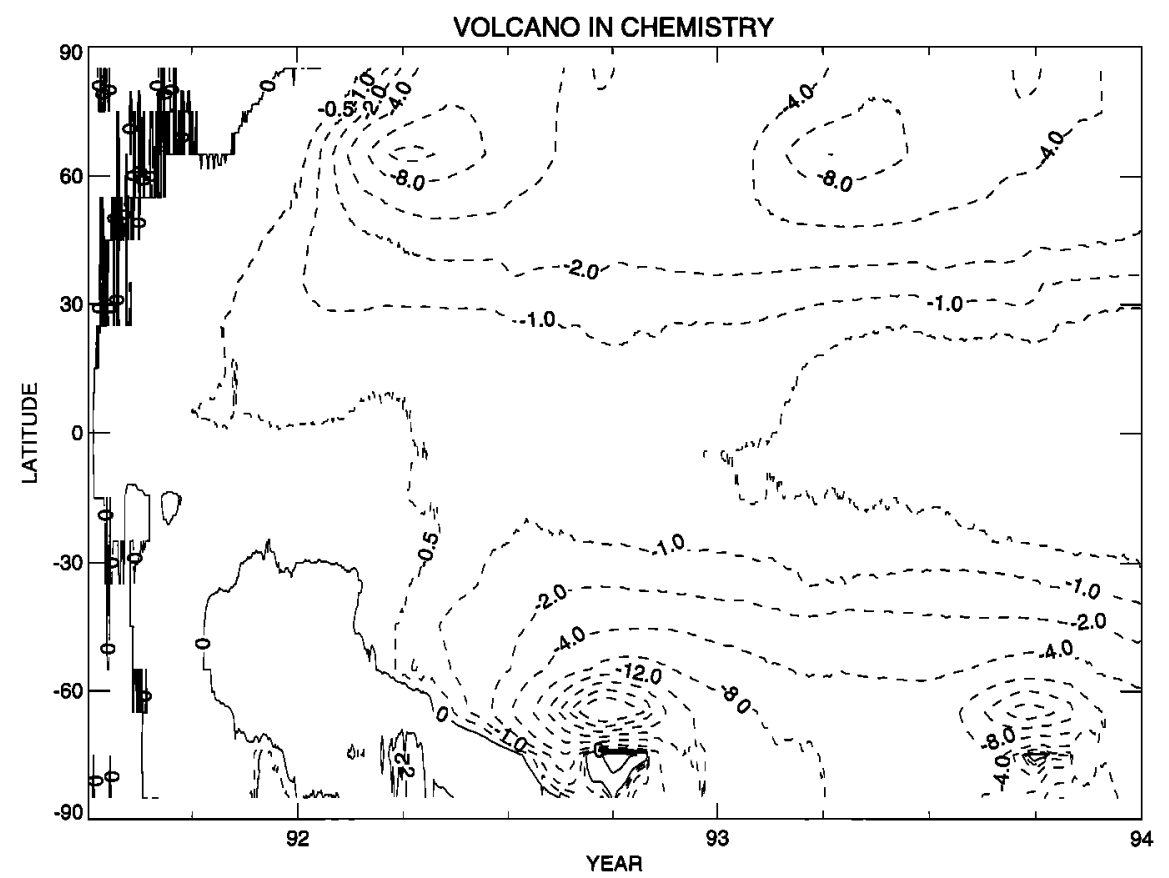

Figure 8. Percent changes in column ozone due to chemistry perturbation. Contour intervals are $-24,-20$, $-16,-12,-8,-4,-2,-1,-0.5,0,2,4,6$.

southern hemisphere is approximately a factor of 2 larger than the northern hemisphere response. In both the northern and the southern hemispheres, the springs of 1992 are characterized by larger column ozone reductions than the springs of 1993 .

The results shown here are different from those shown in chapter 6 of $W M O$ [1995], which were obtained from the GSFC-fixed circulation model. Differences arise partly from the different circulations in the fixed and the interactive models and from the radiative and dynamic feedbacks which are present in the interactive model but not in the fixed circulation model; but by far the largest contributor to the differences are the very different aerosol surface area densities used in the two simulations. The WMO simulations specified an idealized scenario to describe the Mount Pinatubo aerosol perturbation. The background aerosol SADs used there were those shown in the work of WMO [1991] and differed substantially from the background SADs used in this study. In the tropics the background SADs we used were more than a factor of 3 greater than the WMO background SADs. For the volcanic perturbation the WMO scenario arbitrarily specified multiplying the background by a factor of 30 in June 1991, with an exponential decay time constant of 1 year. This yields very different volcanic surface area densities, both in magnitude and in latitudinal and altitudinal pattern, from those used in the current study.

In order to understand the reasons for the changes in column $\mathrm{O}_{3}$ we show percent changes in profile $\mathrm{O}_{3}, \mathrm{ClO}, \mathrm{NO}_{x}$, and $\mathrm{HO}_{x}$ as a function of time in Figures 9, 10, and 11. These figures show the $65^{\circ} \mathrm{N}, 5^{\circ} \mathrm{S}$, and $65^{\circ} \mathrm{S}$ latitudes, respectively. Figure 9 shows that maximum percentage reductions of $\mathrm{O}_{3}$ occur at about 100 mbar in the spring of 1992 and 1993. Peak reductions in the spring of 1993 occur at slightly lower altitudes with a somewhat smaller magnitude. The reductions in $\mathrm{O}_{3}$ are preceded by large increases in $\mathrm{ClO}$ of up to $400 \%$ that occur about 1 month prior to the peak $\mathrm{O}_{3}$ reductions. The peak percent increases in $\mathrm{ClO}$ are well correlated in altitude with the peak percent reductions in $\mathrm{O}_{3}$. In addition to the large increases in $\mathrm{ClO}$ there are significant reductions in $\mathrm{NO}_{x}$, as would be expected from the heterogeneous reactions that are being driven by the induced increases in sulfate SAD.

The changes in $\mathrm{HO}_{x}$ shown in Figure 9 are interesting. The peak increases in $\mathrm{HO}_{x}$ of about $200 \%$ occur in the late summer and fall rather than in the spring. Increases in $\mathrm{HO}_{x}$ are expected to result from the volcanically induced increase in the rate of conversion of $\mathrm{N}_{2} \mathrm{O}_{5}$ to $\mathrm{HNO}_{3}$, a heterogeneous reaction which does not depend on cold temperatures to proceed at a high rate. $\mathrm{HO}_{x}$ is produced when the $\mathrm{HNO}_{3}$ formed by this heterogeneous process photolyzes, suggesting that the increases in $\mathrm{HO}_{x}$ will mainly occur during the summer, as is observed. On the other hand, the heterogeneous reactions which directly activate chlorine require cold temperatures and thus occur primarily in the winter lower stratosphere. The fact that the largest decreases in $\mathrm{O}_{3}$ occur just after the winter indicates that the most important heterogeneous processes at this latitude are those that directly activate chlorine.

Equatorial changes in $\mathrm{O}_{3}, \mathrm{ClO}, \mathrm{NO}_{x}$, and $\mathrm{HO}_{x}$ are shown in Figure 10. Maximum decreases in $\mathrm{O}_{3}$ are about $2 \%$ and occur midway through 1992. The altitude of the peak percentage $\mathrm{O}_{3}$ reductions is located around 25 mbar throughout the latter half of 1991. The location of the peak reductions lowers slowly throughout 1992 and 1993, occurring near 50 mbar in the latter part of 1993. As at higher latitudes, increases in $\mathrm{ClO}$ and $\mathrm{HO}_{\boldsymbol{x}}$ and decreases in $\mathrm{NO}_{x}$ occur, as expected. For the most part, $\mathrm{O}_{3}$ decreases occur where $\mathrm{ClO}$ increases. However, above about 15 mbar, there are small increases in $\mathrm{O}_{3}$. In this region the fraction of $\mathrm{O}_{3}$ loss due to $\mathrm{NO}_{x}$ chemistry is large enough so that the reductions in $\mathrm{NO}_{x}$ that occur in the same location reduce $\mathrm{O}_{3}$ loss more than the increases in $\mathrm{ClO}$ and $\mathrm{HO}_{x}$ increase it. Hence increases in $\mathrm{O}_{3}$ occur.

Figure 11 depicts high southern hemisphere latitude changes in $\mathrm{O}_{3}, \mathrm{ClO}, \mathrm{NO}_{x}$, and $\mathrm{HO}_{x}$. There are many similarities with the northern hemisphere as can be seen by comparing Figure 11 with Figure 9. Peak $\mathrm{O}_{3}$ losses occur at slightly lower alti- 


\section{VOLCANO IN CHEMISTRY}
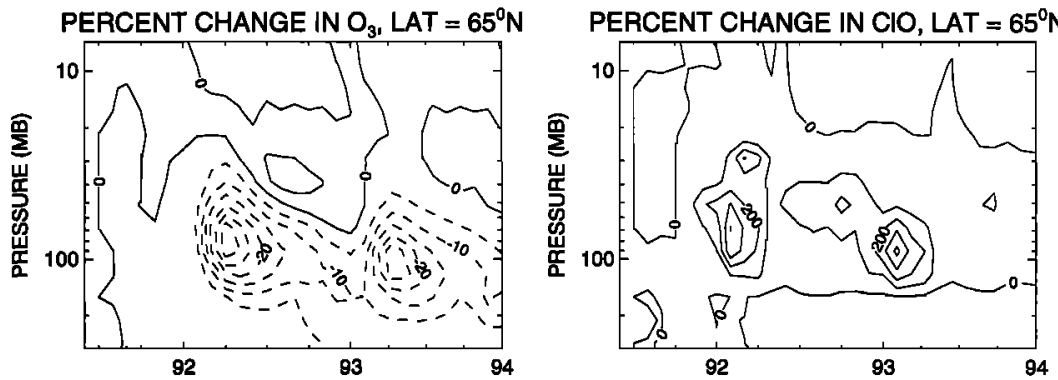

PERCENT CHANGE IN NO ${ }_{x}$, LAT $=65^{\circ} \mathrm{N}$
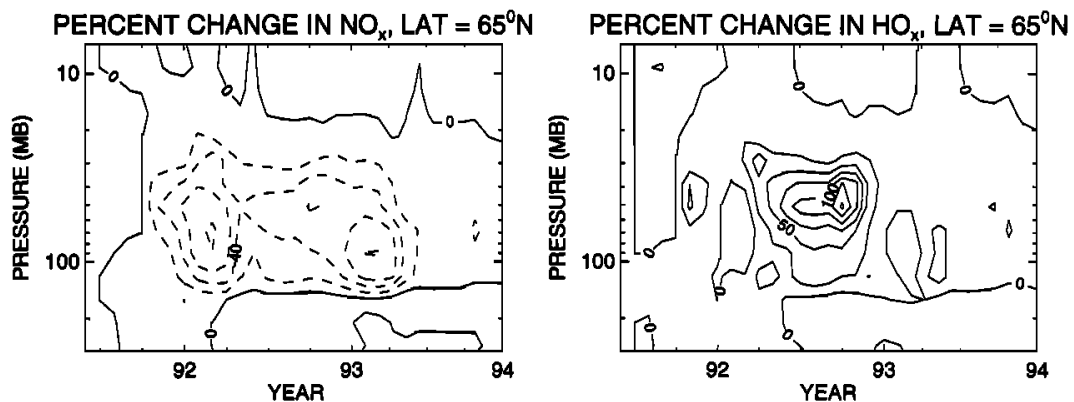

Figure 9. Percent changes in ozone and other constituent profiles at $65^{\circ} \mathrm{N}$ due to chemistry perturbation. The contour intervals are evenly spaced.

tudes but occur in the southern hemisphere springtime, as in the northern hemisphere. The $\mathrm{O}_{3}$ losses are preceded by substantial increases in $\mathrm{ClO}$. Increases in $\mathrm{HO}_{x}$ occur in the summer. The increases in $\mathrm{ClO}$ are generally accompanied by decreases in $\mathrm{NO}_{x}$. One difference between the northern and the southern hemisphere is a substantial increase in southern hemisphere $\mathrm{NO}_{x}$, peaking at about 100 mbar just after the largest reductions in $\mathrm{O}_{3}$ have occurred. In the southern hemisphere, volcanically perturbed heterogeneous reactions con- vert more $\mathrm{ClONO}_{2}$ to $\mathrm{HNO}_{3}$ than in the northern hemisphere over the course of the winter. At the beginning of spring, there is therefore more $\mathrm{HNO}_{3}$ available to photolyze and form $\mathrm{NO}_{x}$ than in the northern hemisphere. The result is an increase in $\mathrm{NO}_{x}$ and a slight decrease in $\mathrm{ClO}$ in the southern hemisphere at the 100 mbar level which does not occur in the northern hemisphere.

Heating rate perturbation. We now discuss the effects of including the volcanic aerosol only in the heating rates. In

\section{VOLCANO IN CHEMISTRY}
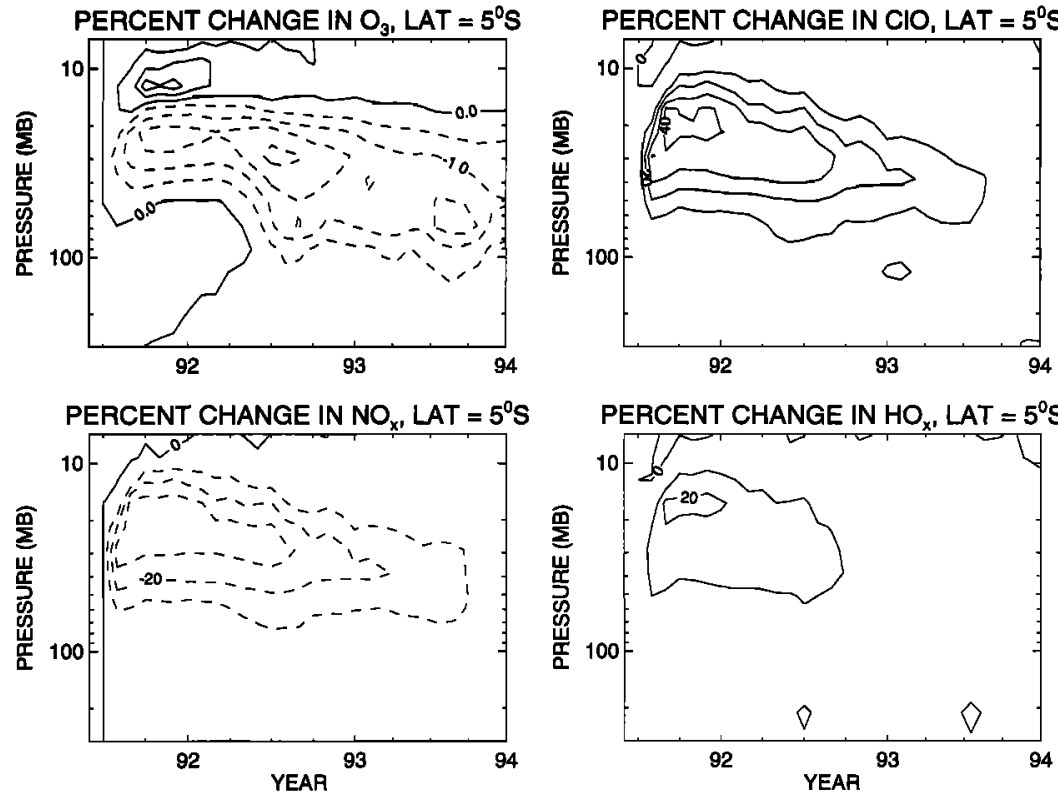

Figure 10. Same as Figure 9 but for $5^{\circ}$. 


\section{VOLCANO IN CHEMISTRY}
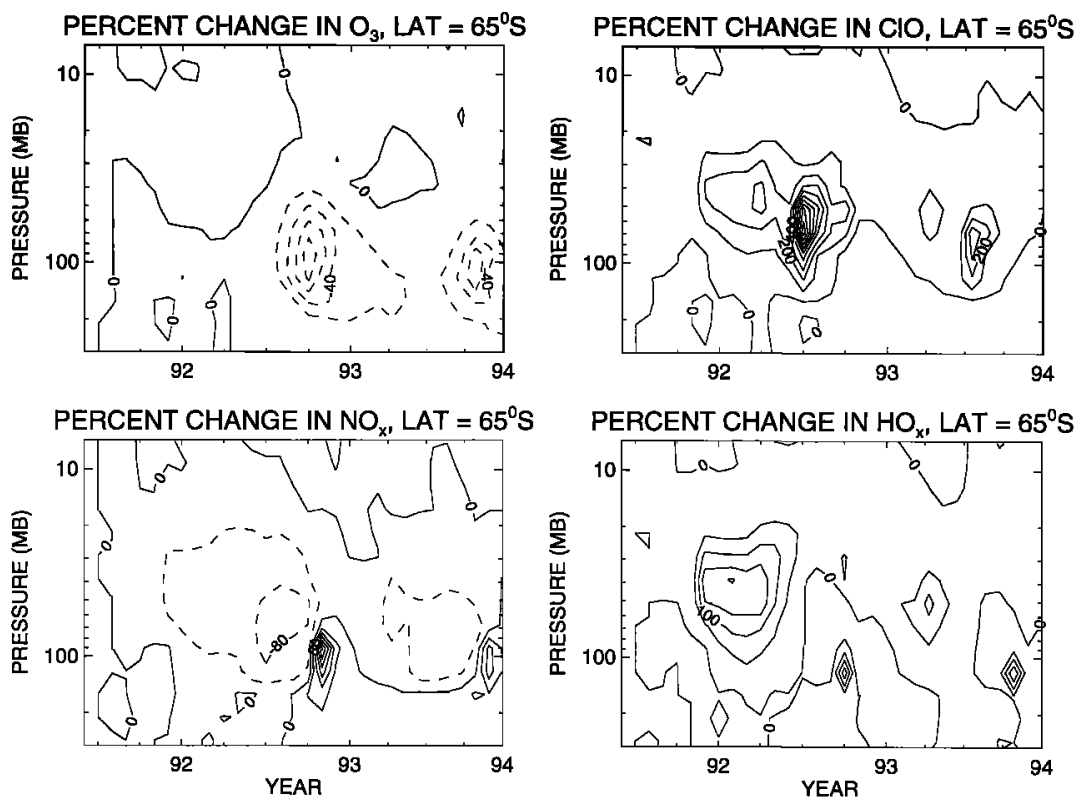

Figure 11. Same as Figure 9 but for $65^{\circ} \mathrm{S}$.

order to illustrate the relative importance of solar heating and infrared heating and the influence of tropospheric clouds on the heating rate perturbation, we show in Figure 12 profiles of the solar, infrared, and net heating rate differences for both clear and cloudy skies. The temperature profile used in these computations is an October 1991 monthly mean equatorial profile from the NMC data set, while the ozone profile is from the SBUV climatology given by McPeters et al. [1984]. We have chosen observed profiles in order that the temperature and ozone profile be the same for the perturbed and unperturbed and the clear and cloudy cases. These profiles would be differ- ent in the model runs due to the feedbacks between heating rates, temperatures, and ozone profiles which occur in the model. For both clear and cloudy skies the perturbation in the solar heating is $\sim 0.1 \mathrm{~K} / \mathrm{d}$. For clear skies the perturbation in the infrared heating dominates, with an increased net heating of $1 \mathrm{~K} / \mathrm{d}$ at $25 \mathrm{~km}$. However, in the presence of tropospheric clouds the perturbation has turned to a small heating of $0.1 \mathrm{~K} / \mathrm{d}$ below about $24 \mathrm{~km}$ and a net cooling of $0.3 \mathrm{~K} / \mathrm{d}$ at $28 \mathrm{~km}$. The clouds provide a radiating lower surface in the infrared which is at much colder temperatures than the ground and thus greatly reduce the upwelling radiative flux reaching the strato-
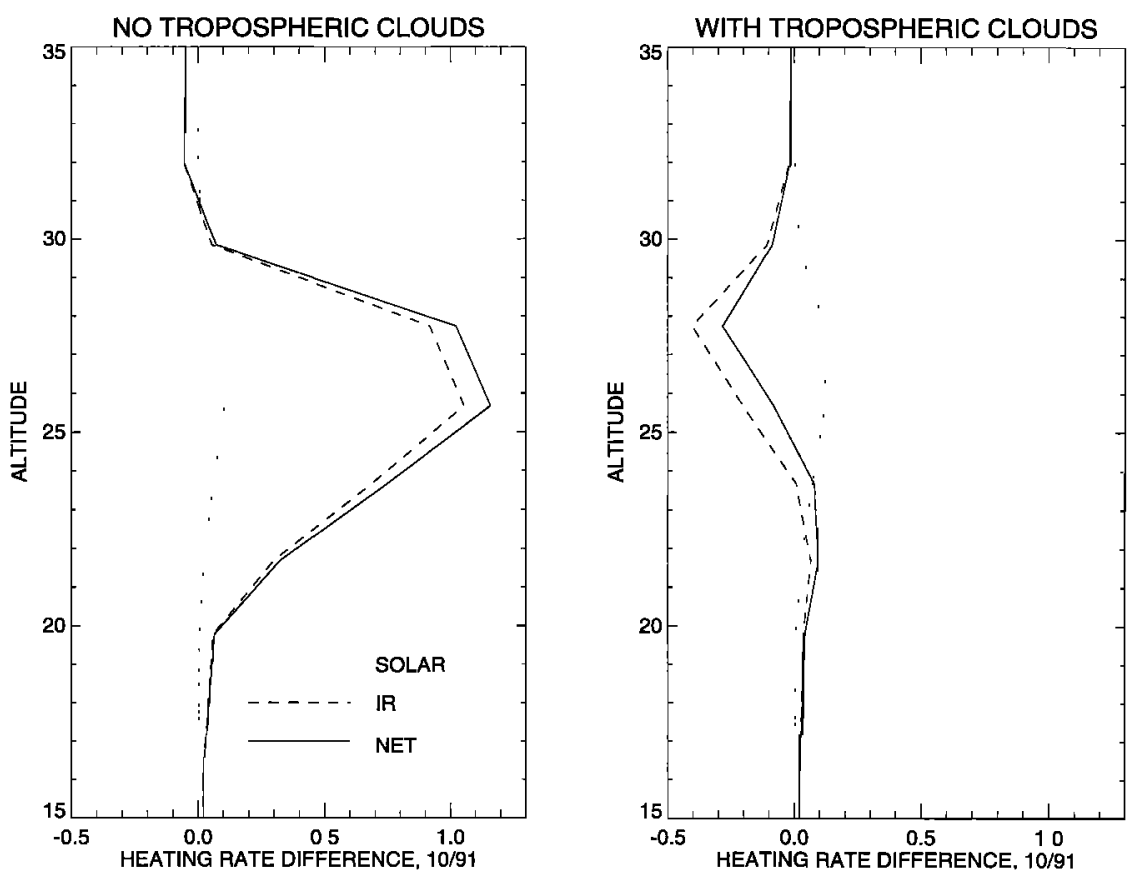

Figure 12. Heating rate difference profiles with and without clouds. Units are $\mathrm{K} / \mathrm{d}$. 


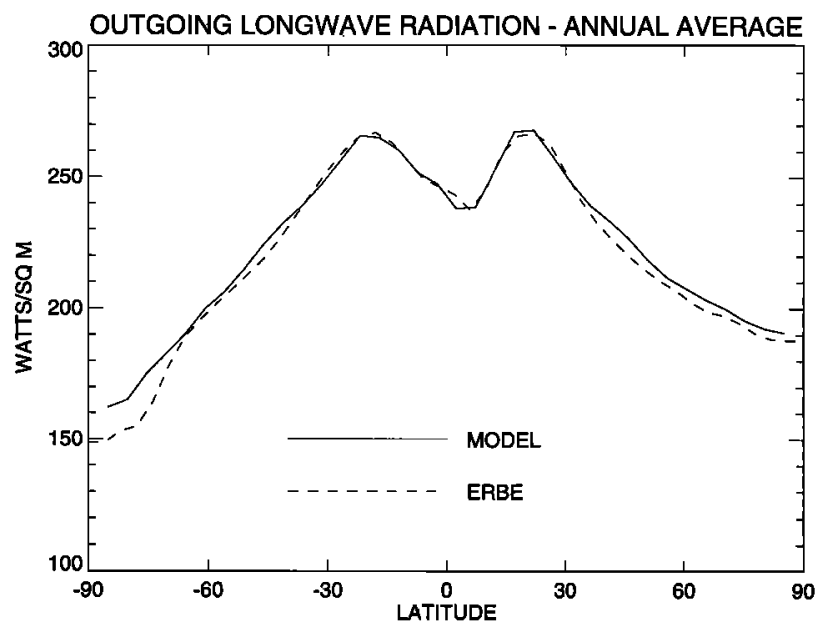

Figure 13. Control run outgoing longwave radiation compared to Earth Radiation Budget Experiment (1986-1988) data.

sphere. The figure emphasizes the importance of the lower lying cloud deck in determining the heating rate perturbation.

Cloud fields were specified in such a way that the modelcomputed annually averaged upwelling flux at the top of the atmosphere agreed with observations. The clouds consisted of a black cloud with a top at 700 mbar and a fraction of $50 \%$ at all latitudes and, at some latitudes, a cirrus cloud with a top at $250 \mathrm{mbar}$ and a latitudinally varying cloud fraction. The cirrus cloud fractions were nonzero only in the tropics, where maximum cloud fractions were $45 \%$, and in the high southern latitudes, where clouds fractions were as large as $70 \%$. Cloud emissivities were determined from the parameterization of Platt and Harshvardhan [1988]. Figure 13 shows the compari- son of the computed top of the atmosphere flux with 19861988 observations from the Earth Radiation Budget Experiment (ERBE). The agreement is better than $10 \%$.

Figure 14 shows changes computed by the model as a result of including the volcanic perturbation in the heating rates. The figure shows October 1991 temperature changes (top left) and vertical velocity changes (bottom left) as a function of latitude and height. There are temperature increases as high as 1.5-2.0 $\mathrm{K}$ from about $20^{\circ} \mathrm{S}$ to $30^{\circ} \mathrm{N}$ between 21 and $25 \mathrm{~km}$, with a maximum increase at $24 \mathrm{~km}$. It is the temperature contrast between the cold stratosphere and the relatively warmer troposphere that is responsible for the heating of the aerosol by upwelling radiation from lower in the atmosphere. The figure (top right) shows the variation of the computed temperature differences as a function of time and altitude at a latitude of $7.3^{\circ} \mathrm{S}$, where the computed temperature difference was a maximum. One can see that the location of the maximum temperature perturbation falls in altitude with time, from 24 to about $20 \mathrm{~km}$, following the bulk of the aerosol cloud. The maximum change of $3 \mathrm{~K}$ at $20 \mathrm{~km}$ does not occur in the model until later in 1992. At this time the observed extinction data show that the largest aerosol mass has reached lower altitudes, where the lower temperatures increase the stratosphere-troposphere temperature contrast and result in more heating.

The vertical velocity changes shown in Figure 14 (bottom left) show increased low latitude upwelling of $0.02-0.05 \mathrm{~mm} / \mathrm{s}$ and increased middle-latitude downwelling of $0.02-0.04 \mathrm{~mm} / \mathrm{s}$. From July 1991 until early 1992, an increase in vertical velocity of roughly $0.04-0.06 \mathrm{~mm} / \mathrm{s}$ was computed at $20^{\circ} \mathrm{N}$ and $22-24$ $\mathrm{km}$, which corresponds to about $0.13 \mathrm{~km} / \mathrm{month}$.

Finally, Figure 14 (bottom right) shows the percent change in column ozone due to the heating rate perturbation as a function of time and latitude. The upwelling results in lowlatitude column ozone decreases of $1-2 \%$ which are a maxi-

\section{VOLCANO IN HEATING RATES}
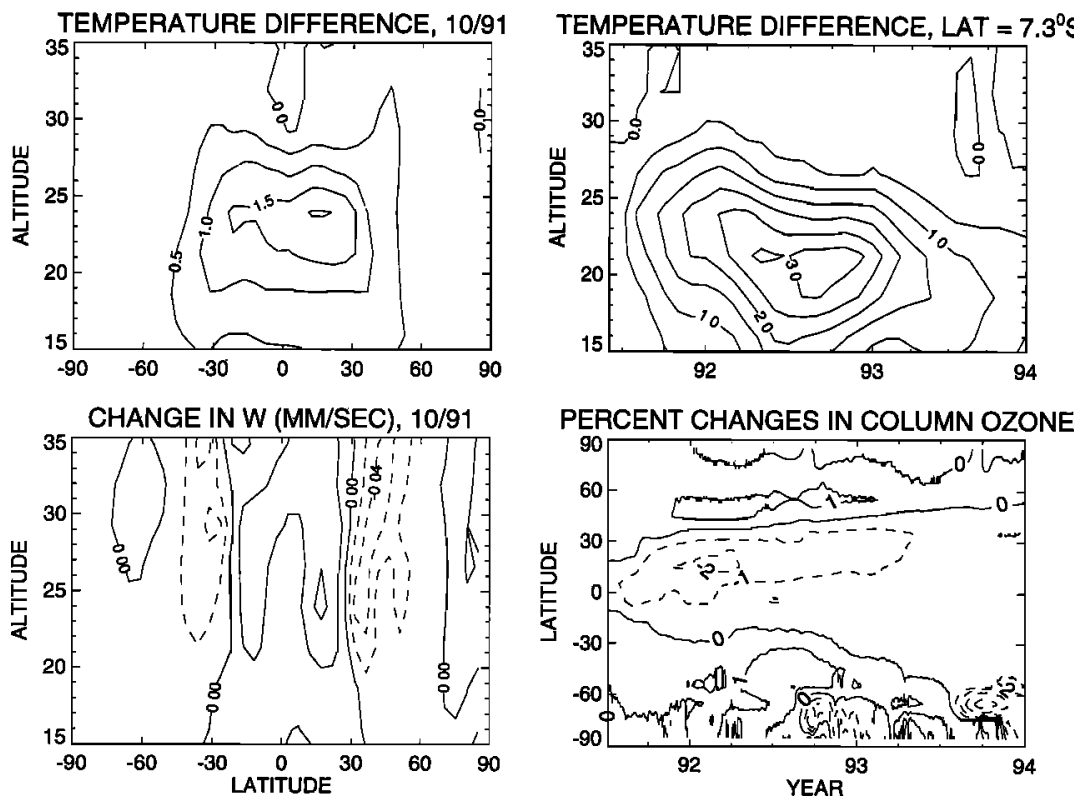

Figure 14. Temperature $(\mathrm{K})$, vertical velocity $(\mathrm{mm} / \mathrm{s})$, and column ozone percent changes due to heating rate perturbation. Contour intervals for vertical velocity (bottom left) are $-0.04,-0.02,0,0.02$, and 0.04 . Contour intervals for column ozone changes (bottom right) are $-8,-4,-2,-1,0$, and $1,2$. 


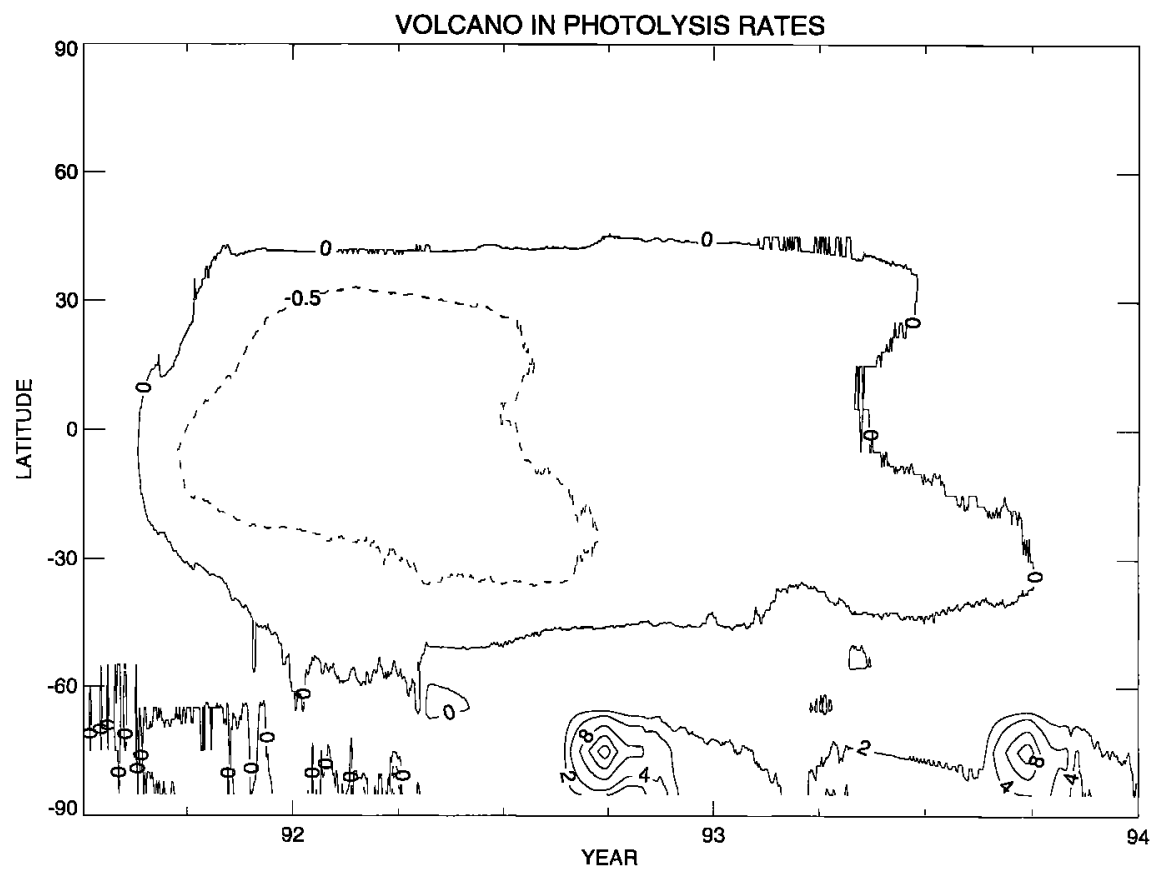

Figure 15. Percent changes in column ozone due to photolysis rate perturbation. Contour intervals are -0.5 , $0,2,4,8$, and 12 .

mum at $15^{\circ} \mathrm{N}$ in early 1992 . These are accompanied by midlatitude increases of $1 \%$ which arise from the increased downwelling at these latitudes. Examination of the ozone profile changes (not shown) at $15^{\circ} \mathrm{N}$ in early 1992 shows losses of $\sim 0.5 \mathrm{ppmv}$ at $23-24 \mathrm{~km}$. The upwelling that has occurred since July 1991 has led to a lifting of the ozone profile by about $1 \mathrm{~km}$, in good agreement with the 1-2 km uplift reported by Hofmann et al. [1994]. Higher up, at 31-34 km, ozone increases of $\sim 0$ i-0.2 ppmv were computed. At these altitudes, which are above the ozone peak, increased upwelling brings up higher ozone values from below.

The high southern latitude springtime decreases that are computed in 1992 and 1993 are due to an interesting feedback of the perturbed dynamics on the chemistry in the model. There is increased downwelling computed during these times at these latitudes, which brings down higher amounts of water vapor from the middle stratosphere. This in turn leads to an enhancement of the surface area densities of the polar stratospheric clouds so heterogeneous conversion reactions activating chlorine and depleting ozone can take place to a greater extent.

Our heating perturbation is significantly lower than previous estimates. In the months immediately following the eruption we get a net tropical heating increase of roughly $0.1 \mathrm{~K} / \mathrm{d}$ in the tropics. Kinne et al. [1992] and Tie et al. [1994] compute a net tropical heating perturbation of the order of $0.3 \mathrm{~K} / \mathrm{d}$, Pitari [1992] computes one of $0.2 \mathrm{~K} / \mathrm{d}$, while Kinnison et al. [1994] compute a value of $0.48 \mathrm{~K} / \mathrm{d}$. In the case of Tie et al. [1994] this difference appears to be due to the fact that their aerosol microphysical model predicts much more aerosol initially than observations, surface area densities peaking in July 1991 at 75 $\mu \mathrm{m}^{2} / \mathrm{cm}^{3}$ versus $25 \mu \mathrm{m}^{2} / \mathrm{cm}^{3}$ from observations. This difference gives rise to significantly higher perturbations in the temperature and dynamics of Tie et al. [1994] than in the present work.

Photolysis rate perturbation. Figure 15 shows the calculated percent changes in column ozone as a function of time and latitude due to the inclusion of the volcanic aerosol per- turbation in only the photolysis rate computation. The result is a $0.5 \%$ reduction of the column in the low latitudes occurring in late 1991 through the middle of 1992 and 8-10\% increases in the high southern latitudes during the springs of 1992 and 1993. In order to understand the low-latitude perturbations, the percent changes in the ozone profile at $5^{\circ} \mathrm{S}$ are shown in Figure 16a. It shows ozone losses up to $5 \%$ below 20-30 mbar and increases of $1 \%$ above 20 mbar. In the model runs, there are photolysis rate changes due both to extinction of radiation by the aerosol and to changes in the overhead ozone column. Figure $16 \mathrm{~b}$ shows the ratio of $J\left(\mathrm{O}_{2}\right)$ for the volcanic run relative to the background run and the corresponding ratio for $J\left(\mathrm{O}_{3}\right)$ at a latitude of $15^{\circ} \mathrm{S}$ and a pressure of $12 \mathrm{mbar}$. The small decrease of $J\left(\mathrm{O}_{2}\right)$ leads to a reduction in the rate of production of ozone. The larger decrease of $J\left(\mathrm{O}_{3}\right)$ leads to a reduction in the $[\mathrm{O}] /\left[\mathrm{O}_{3}\right]$ ratio, thus lowering the rate of loss of ozone by catalytic cycles. Since at $12 \mathrm{mbar}, J\left(\mathrm{O}_{3}\right)$ is reduced much more than $J\left(\mathrm{O}_{2}\right)$, there is a net increase in ozone. Figure $16 \mathrm{c}$ shows the same ratios except at a pressure of 51 mbar. In the lower stratosphere the rate of ozone production, determined by $J\left(\mathrm{O}_{2}\right)$, is reduced more than the rate of ozone loss, leading to a net loss of ozone. In the total ozone column the contributions from the lower stratosphere outweigh those from the middle and upper stratosphere, leading to a net reduction in column ozone at low latitudes.

We now focus on the springtime high southern latitude increases in column ozone, which peak at $75^{\circ} \mathrm{S}$, shown in Figure 15. Column ozone increases in the volcanic run relative to the background run because less $\mathrm{ClO}$ is activated in the volcanic run than the background run when the Sun returns in the austral spring, and the loss of ozone decreases. $\mathrm{Cl}_{y}$ activation in the volcanic run is smaller because more $\mathrm{Cl}_{y}$ is stored as $\mathrm{HOCl}$ rather than $\mathrm{Cl}_{2}$ in the volcanic run during polar night compared to the background run. $\mathrm{HOCl}$ is less readily photolyzed than $\mathrm{Cl}_{2}$, leading to a smaller buildup of $\mathrm{ClO}$.

The primary cause of this change in behavior is a lowered 


\section{VOLCANO IN PHOTOLYSIS RATES}

(a) PERCENT CHANGE IN $\mathrm{O}_{3}, 5^{\circ} \mathrm{S}$

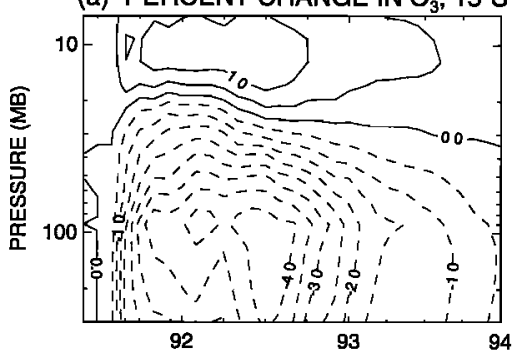

(c) J RATIOS, $15^{\circ} \mathrm{S}, 51 \mathrm{mb}$

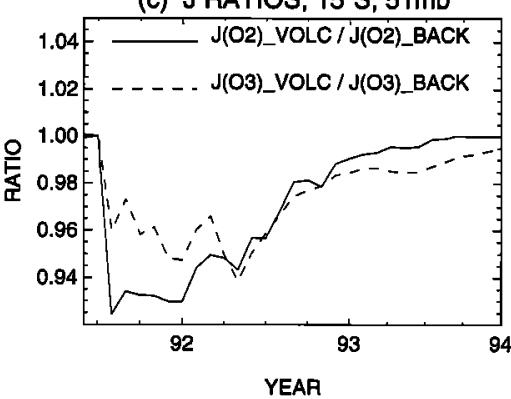

(b) J RATIOS, $15^{\circ} \mathrm{S}, 12 \mathrm{mb}$

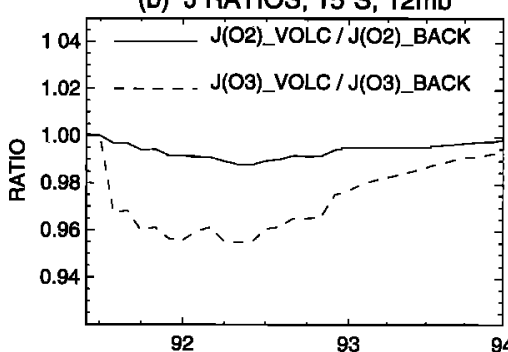

(d) $\mathrm{ClONO}_{2}, 75^{\circ} \mathrm{S}, 51 \mathrm{mb}$

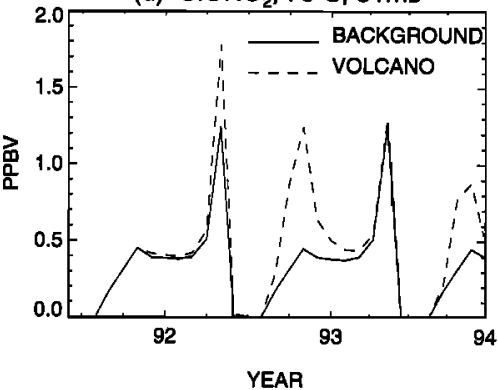

Figure 16. (a) Ozone changes, (b) and (c) $J\left(\mathrm{O}_{2}\right)$ and $J\left(\mathrm{O}_{3}\right)$ ratios, and (d) $\mathrm{ClONO}_{2}$ changes due to photolysis rate perturbation.

$\mathrm{ClONO}_{2}$ photolysis coefficient in the volcanic run. Lower stratospheric photolysis rates for $\mathrm{ClONO}_{2}$ are reduced 20$30 \%$ by the volcanic aerosol just before and after austral winter when the solar zenith angle is large. This leads to increases in $\mathrm{ClONO}_{2}$, as shown in Figure 16d which compares volcanic to nonvolcanic $\mathrm{ClONO}_{2}$ mixing rations at $75^{\circ} \mathrm{S}$ and $51 \mathrm{mbar}$. The ratio of $\mathrm{HCl} / \mathrm{ClONO}_{2}$ is therefore reduced in the volcanic run at the beginning of the austral winter. This leads to larger amounts of $\mathrm{Cl}_{y}$ being stored by heterogeneous reactions in $\mathrm{HOCl}$ rather than $\mathrm{Cl}_{2}$, both of which act as nighttime reservoirs for $\mathrm{Cl}_{y}$.

Full chemistry and radiation perturbation. Figure 17 shows the resulting column ozone changes with the full perturbation, when the effects of the volcanic aerosol are included in the heterogeneous chemistry, the heating rates, and the photolysis rates. Low-latitude column reductions of $2-3 \%$ are

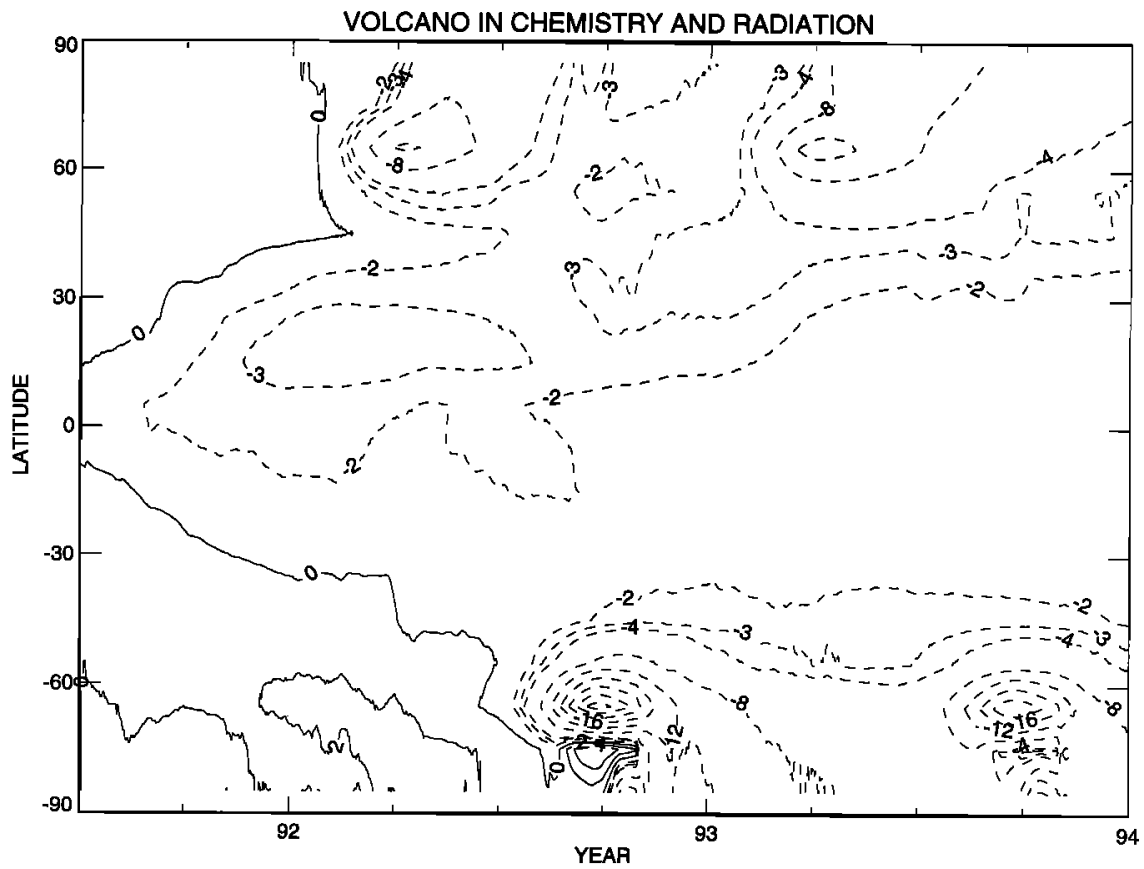

Figure 17. Percent changes in column ozone due to full chemistry and radiation perturbation. Contour intervals are $-28,-24,-20,-16,-12,-8,-4,-3,-2,0$, and 2,4 . 
computed from September 1991 until late 1992, with a maximum loss of $3.5 \%$ occurring in early 1992 . The reductions fall below $2 \%$ after late 1992 . Roughly, half of these low-latitude losses arise from the heating rate perturbation, with the chemistry and the photolysis rate perturbations each contributing about one quarter of the total loss. The effects seem to be additive at these latitudes. In the high latitudes there are springtime depletions of $8-10 \%$ in the northern hemisphere, and $12-20 \%$ in the southern hemisphere associated with the appearance of the Antarctic ozone hole. In both hemispheres the maximum depletions occur off the pole, at a latitude of $65^{\circ}$. The high northern latitude losses are a result mainly of the additional heterogeneous conversion occurring on volcanic aerosol surfaces. In the southern high latitudes both the larger volcanic aerosol surfaces and the enhanced PSC surfaces arising from the increased downwelling contribute to the losses. There is also a suggestion of an increase in column ozone, of the order of $2-4 \%$, at $75^{\circ} \mathrm{S}$ in the 1992 austral spring. This is a remnant of the $8-12 \%$ increases at that latitude due to the effects of the aerosol on photolysis rates, shown in Figure 15.

Global variations in observed column ozone following the Mount Pinatubo eruption have been reported by Zerefos et al. [1994] (hereinafter referred to as Z94) and Randel et al. [1995] (hereinafter R95). Figure 4 in Z94 presents zonal mean ozone anomalies between $60^{\circ} \mathrm{S}$ and $60^{\circ} \mathrm{N}$ after the removal of the quasi-biennial oscillation (QBO), El Nino-Southern Oscillation (ENSO), and trend components. It shows tropical losses of 2-4\% in September-November 1991 and southern subtropical losses of $2-4 \%$ in June-November 1992. In the higher northern latitudes there is a $6 \%$ depletion at $60^{\circ} \mathrm{N}$ in December 1991 to March 1992 and an $8 \%$ depletion at $60^{\circ} \mathrm{N}$ in February-March 1993. In the southern high latitudes there are positive anomalies in the summers of 1992 and 1993, with an area of negative anomalies (less than 2\%) in SeptemberNovember 1992. Figure 7 in R95 shows zonal mean column ozone anomalies with the effect of the QBO removed between $90^{\circ} \mathrm{S}$ and $90^{\circ} \mathrm{N}$. The tropical and southern subtropical anomalies shown are very similar to those given in Z94. The changes in the higher northern latitudes, however, are somewhat different. R95 show losses of 10\% in February-March 1992 poleward of $60^{\circ} \mathrm{N}$ and losses of $10-12 \%$ in February-March 1993. The magnitude and areal extent of the depletion is larger and reaches to lower latitudes in 1993 than in 1992. In both years the high northern latitude losses shown in R95 begin early in the winter and persist with a magnitude less than $4 \%$ into the northern hemisphere summer. The southern hemisphere variations shown by R95 are quite different than those given by Z94. R95 show depletions of $10-20 \%$ associated with the Antarctic ozone hole in October-December 1993.

The magnitude of our model computed tropical ozone losses of 2-3.5\%, which begin in September 1991, are in good agreement with these observations. However, the maximum computed depletion does not occur until early 1992, while in the observations, the maximum occurs in the fall 1991. In the middle and high northern latitudes the 8-10\% losses computed by the model agree fairly well with the data presented by R95, as does the greater magnitude and spatial extent of the 1993 depletion compared with that of 1992 . The timing of the middle and high northern latitude losses in both years appears to be shifted about two months later than observations. In the model these losses do not begin until the springtime, while in the observations they begin in early winter. This is probably related to the fact that the model does not take into account the off-the-pole motion of the vortex, which would allow air parcels to experience sunlight at earlier times. The high northern latitude depletion is larger in 1993 than in 1992 in our model, in agreement with $\mathrm{R} 95$. This is because the radiative perturbation, which gives rise to ozone increases due to downwelling, has fallen to lower magnitudes in 1993 compared to 1992. The fact that Tie et al. [1994] compute greater highlatitude ozone losses in 1992 than in 1993 is probably related to the fact that their radiative perturbation is much larger than ours. Similarly, Kinnison et al. [1994] conclude that in their model the heterogeneous effects are not large enough to outweigh the production of ozone at high latitudes from increased circulation. This may be a result of the larger heating rate anomaly in their radiative perturbation.

In the southern hemisphere the modeled high-latitude springtime losses of $12-20 \%$ agree well with the losses of 10-20\% shown by R95. Their Figure 7 also shows a small area with ozone increased by $2-4 \%$ centered at about $75^{\circ} \mathrm{S}$ in October 1992. Our results also show this feature, which in our model is mainly due to the effects of the perturbed photolysis rates as can be seen in our Figure 15. This feature is absent at the corresponding time and place in 1993 in both our results and the observations.

Figure 18 shows computed ozone mixing ratio changes in parts per million by volume as a function of time and height at $15^{\circ} \mathrm{N}$ (top left), where the tropical column ozone losses are the greatest, and at $65^{\circ} \mathrm{N}$ (top right). There are decreases larger than $0.3 \mathrm{ppmv}(4-11 \%)$ for the tropical profile at $23 \mathrm{~km}$ from late 1991 to late 1992 and increases larger than $0.2 \mathrm{ppmv}$ (2-4\%) at $31 \mathrm{~km}$ from early to late 1992 . These changes have their origins in the combined chemistry, heating rate, and photolysis rate perturbations. The separate volcanic aerosol perturbation in all three processes led to tropical lower stratospheric ozone decreases and middle and upper stratospheric ozone increases, as has been discussed above. At $65^{\circ} \mathrm{N}$, springtime ozone losses in 1992 and 1993 as large as 0.6-0.8 ppmv are calculated at $15-17 \mathrm{~km}$, with enhanced ozone at higher altitudes during and after the northern hemisphere summer of 1992. As shown above, these high latitude calculated changes are due mainly to heterogeneous chemistry. Grant et al. [1994] report that January 1992 ozonesonde profiles in Brazzaville, Congo $\left(4^{\circ} \mathrm{S}\right)$, show $10 \%$ losses of ozone below the peak and roughly $6 \%$ increases above the peak, compared with a SAGE II climatology. Hofmann et al. [1993] report lower than normal ozone below 20-24 km and higher than normal ozone above about $26 \mathrm{~km}$ in Hilo, Hawaii $\left(20^{\circ} \mathrm{N}\right)$, after the volcanic eruption. Also, ozone decreases below the maximum and increases above the maximum at Table Mountain, California $\left(34^{\circ} \mathrm{N}\right)$, were reported by $M c G e e$ et al. [1993]. Thus our modelcomputed ozone profile changes are in good agreement with observations.

Also shown in Figure 18 are the modeled temperature perturbations. Temperature differences at $18.6 \mathrm{~km}$ as a function of time and latitude (bottom left) show increases greater than 2.5 $\mathrm{K}$ in late 1992 in the southern hemisphere low latitudes. Temperature differences at $2.4^{\circ} \mathrm{S}$ as a function of time and altitude (bottom right) show that the altitude of the maximum computed temperature increases begins at $25 \mathrm{~km}$ in 1991 and shifts to lower altitudes in time, as the volcanic aerosol cloud moves to lower altitudes. At this latitude the maximum increase is computed to occur in September 1992 at about $20 \mathrm{~km}$. These calculated low-latitude increases in temperature are due to the perturbation in the heating rates. At the high latitudes in both 


\section{VOLCANO IN CHEMISTRY AND RADIATION}
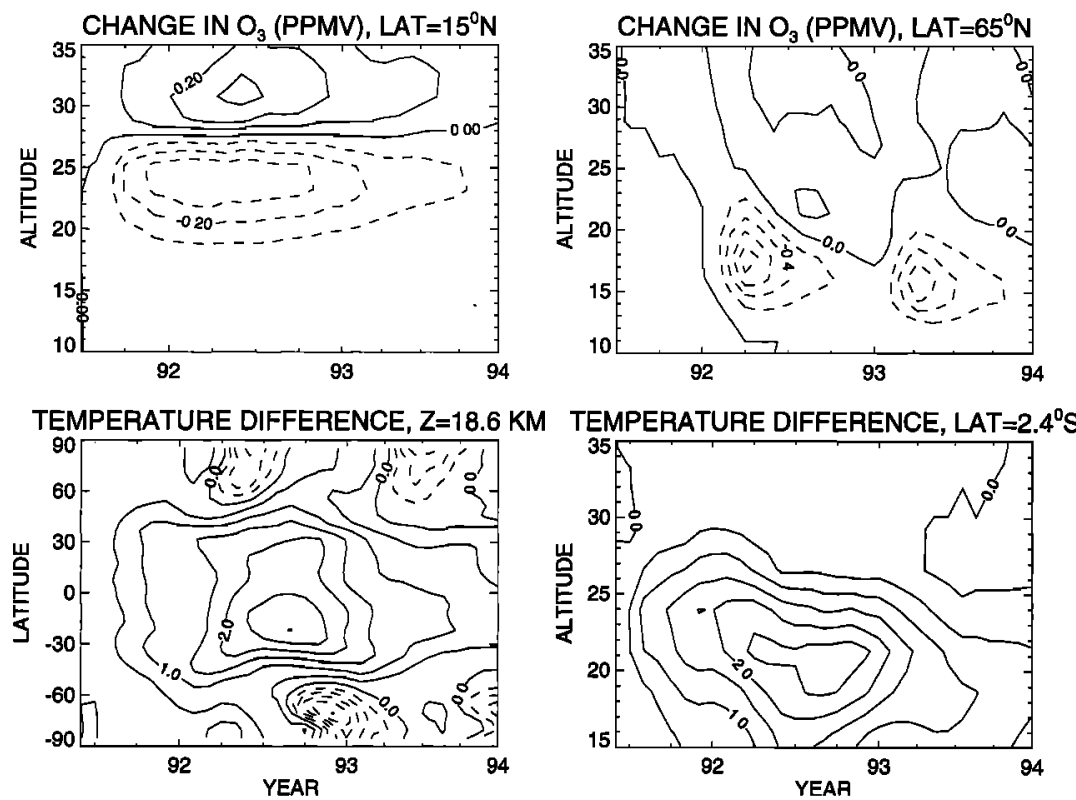

Figure 18. Ozone profile and temperature changes with full perturbation. The contour intervals are evenly spaced.

hemispheres, computed temperature decreases can be seen at $18.6 \mathrm{~km}$ (bottom left), following the computed springtime decreases in ozone. They are evidence of the feedback of the chemically induced ozone losses on the computed heating rates. Decreases of $1.5 \mathrm{~K}$ are computed in the northern hemisphere spring and summer, while somewhat larger decreases of $2 \mathrm{~K}$ are computed in the southern hemisphere spring and summer, as one would expect from the larger southern hemisphere ozone losses which the model calculates.

Labitzke and McCormick [1992] report zonal average tropical anomalies of 2-3 K at 30 and 50 mbar in autumn of 1991 and Hofmann et al. [1993] report 2-3 K anomalies at Hilo, Hawaii, in the 20-25 km layer from autumn 1991 until spring 1992. Randel et al. [1995] show microwave sounding unit (MSU) temperature anomalies, from which the QBO signal has been removed, as a function of time and latitude. They show tropical anomalies of 1-1.5 K from August 1991 to April 1992. The magnitude of our computed tropical temperature perturbations agrees well with these observations, while the timing appears to be late by roughly half a year. Randel et al. [1995] show cold temperature anomalies of about $1 \mathrm{~K}$ in the northern hemisphere polar regions during summer 1993, as do our calculations. They show warm anomalies during northern hemisphere summer 1992, however, which disagrees with our model results. They show high-latitude southern hemisphere springtime positive anomalies of $4 \mathrm{~K}$ in 1992 and negative anomalies of $4 \mathrm{~K}$ in 1993.

Area-weighted globally averaged column ozone amounts between $60^{\circ} \mathrm{S}$ and $60^{\circ} \mathrm{N}$ were determined for the control run with the background aerosol and for the run with the volcanic perturbation in the chemistry and radiation. The model-computed percent changes in the global average ozone as a function of time are shown in Figure 19. Also shown are the weekly averaged differences observed by the TOMS instrument, relative to the average of the years 1979 through 1990. The TOMS ozone data have recently been reprocessed, and we show in this figure the results from the latest version 7 reprocessing. We also show the TOMS differences with the quasi-biennial oscillation (QBO) removed, and with both the QBO and the 11-year solar cycle removed. The QBO and solar cycle contributions were determined using a standard linear multiple regression model, which included terms for the seasonal cycle, linear trend, QBO, and 11-year solar cycle [McPeters et al., 1996; Hollandsworth et $a l ., 1995]$. The differences with QBO removed and with both QBO and solar cycle removed are shown separately because aerosol surface areas and sunspot numbers are correlated to some degree, since the eruption of Mount Pinatubo occurred a few weeks after solar maximum. It has been suggested that this could lead to some aerosol-induced ozone changes being erroneously ascribed to solar effects in statistical analyses of ozone trends [Solomon et al., 1996].

At the end of 1991 the global ozone calculated for the volcanic run is $1 \%$ lower than that for the background run. The computed loss reaches a maximum of $3.2 \%$ around September 1992, after which it begins recovering, reaching a loss of about $1.7 \%$ by the end of 1993 . The maximum ozone loss in the data record occurs in the spring of 1993, somewhat later than in the model. The model-computed global ozone changes are within $1 \%$ in absolute magnitude of those seen in the TOMS data with the QBO removed. The maximum globally averaged column ozone depletions ranged from 2 to $4 \%$ for the test cases in which the planetary wave forcings were varied as shown in Table 1 and discussed above. Figure 20 shows the global average differences calculated for the test cases A through F, compared with the baseline case.

The area-weighted global average temperature perturbations computed by the model at $18.6,21.3$, and $23.9 \mathrm{~km}$ are shown in Figure 21 as a function of time. The temperatures start rising just after the volcanic eruption in June 1991. In December 1991 the peak perturbation of $1.15 \mathrm{~K}$ is at $23.9 \mathrm{~km}$, while in August 1992, when the aerosol cloud has moved to lower altitudes, the peak perturbation of $1.45 \mathrm{~K}$ occurs at 18.6 


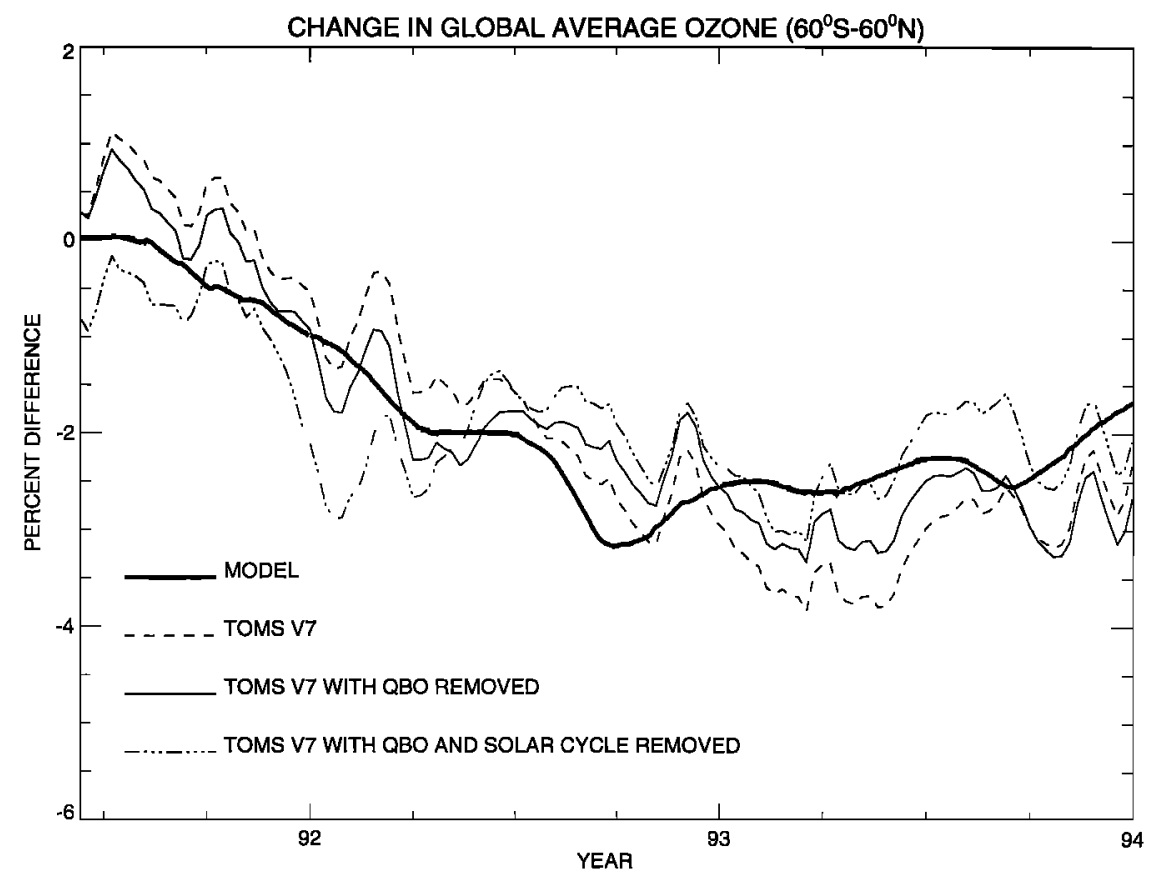

Figure 19. Global average ozone percent changes with full perturbation compared to total ozone mapping spectrometer (TOMS). The TOMS changes are relative to the 1979-1990 TOMS average. The measurements include those from the Nimbus 7 TOMS instrument and the TOMS instrument aboard the Russian Meteor 3 satellite.

$\mathrm{km}$. After early 1992 the temperatures are still rising at 18.6 and $21.3 \mathrm{~km}$, while they start to fall at the higher altitude. These computed temperature perturbations agree fairly well with the MSU global mean anomalies shown in Figure 15 of Randel et al. [1995]. The MSU observations, which are measures of the $150-50$ mbar layer, show a temperature increase peaking at $1.2 \mathrm{~K}$ in late 1991 , with a secondary maximum of 0.7 K at the beginning of 1993 .

Model-calculated percent changes in $\mathrm{HNO}_{3}$ and $\mathrm{NO}_{2}$ column amounts at $45^{\circ} \mathrm{S}$ are shown in Figure 22. Reductions in $\mathrm{NO}_{2}$ and increases in $\mathrm{HNO}_{3}$ first appear after August 1991 when the volcanic aerosol reaches that latitude. The computed

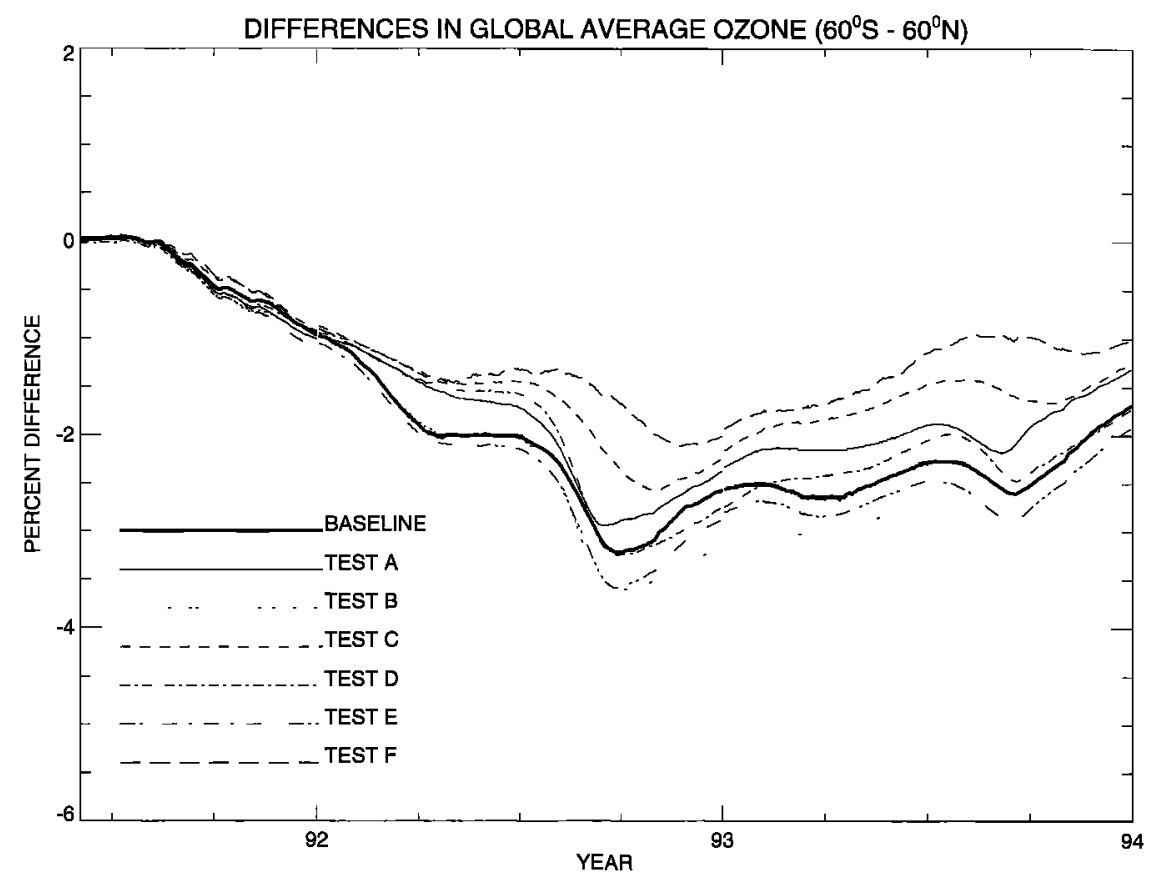

Figure 20. Global average ozone percent changes computed with full perturbation for the baseline case and for tests A-F. 


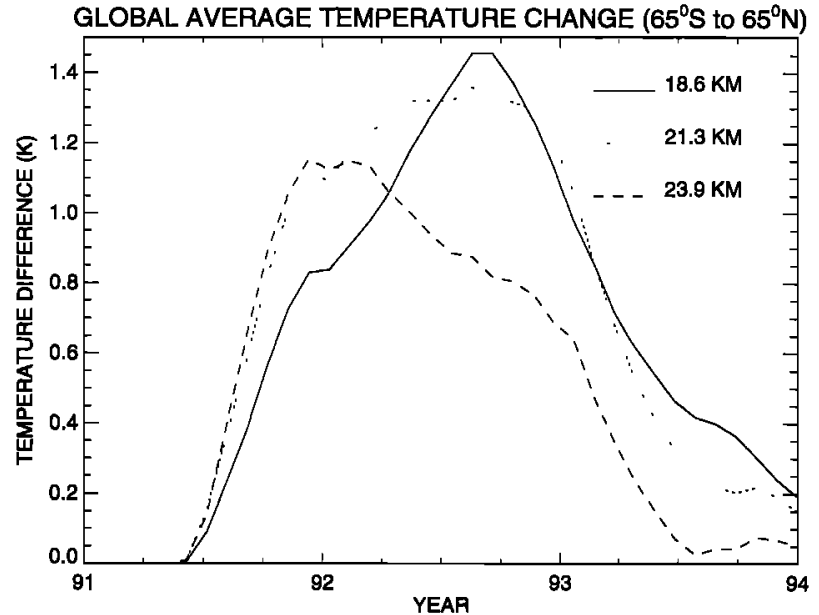

Figure 21. Global average temperature changes for full perturbation.

repartitioning is due mainly to the hydrolysis of $\mathrm{N}_{2} \mathrm{O}_{5}$ (reaction (1)). Maximum computed changes of $20 \%$ occur late in 1991 after which they gradually decrease. Koike et al. [1994] show $\mathrm{HNO}_{3}$ and $\mathrm{NO}_{2}$ observations from Lauder, New Zealand $\left(45^{\circ} \mathrm{S}, 170^{\circ} \mathrm{E}\right)$, compared with two-dimensional model results from Lawrence Livermore National Laboratory (LLNL) and Atmospheric and Environmental Research, Inc. (AER). In the observations, maximum $\mathrm{NO}_{2}$ reductions of $40 \%$ occur late in 1991, while maximum $\mathrm{HNO}_{3}$ increases of $40 \%$ occur in early 1992. Our model-computed changes are low in absolute magnitude compared to the data, as is true for both the LLNL and the AER predictions. The LLNL model predicts a reduction of approximately $10 \%$ in $\mathrm{NO}_{2}$ and an increase of $10 \%$ in $\mathrm{HNO}_{3}$, while the AER model predicts a reduction of $20 \%$ in $\mathrm{NO}_{2}$ and an increase of $10 \%$ in $\mathrm{HNO}_{3}$.

\section{Summary}

We have developed a new radiative-dynamical-chemical interactive two-dimensional model containing a linear planetary wave parameterization. The model incorporates heterogeneous chemistry on the surfaces of both sulfate aerosols and

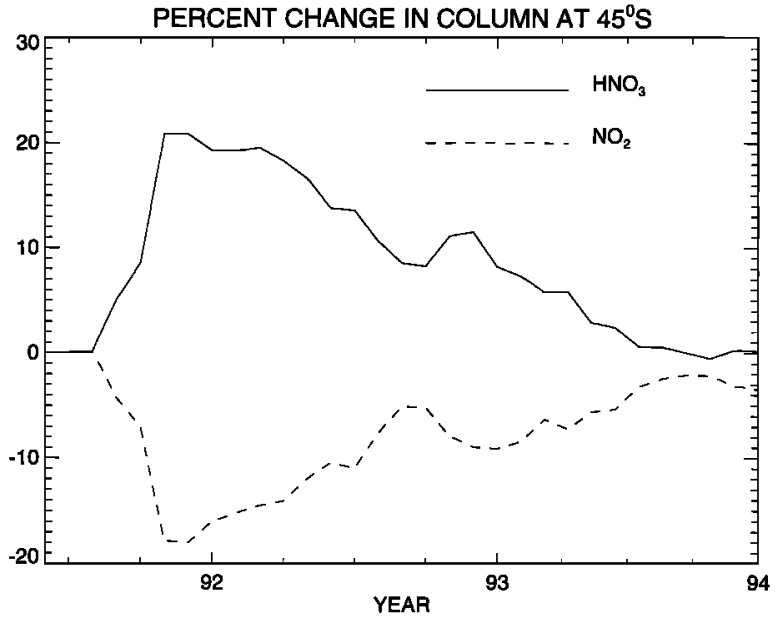

Figure 22. $\mathrm{NO}_{2}$ and $\mathrm{HNO}_{3}$ column percent changes at $45^{\circ} \mathrm{S}$ for full perturbation. polar stratospheric clouds. Modeled temperatures and winds are in rough agreement with climatological values, and computed column ozone amounts are in very good agreement with observations. The model has some difficulty in simulating the breakup of the southern hemisphere winter polar vortex. The southern hemisphere planetary wave forcing parameters were adjusted to give the best overall agreement of the computed column ozone with observations.

The model has been used to study the effects of the Mount Pinatubo aerosol cloud on stratospheric temperatures, dynamics, and chemistry. Aerosol surface area densities and wavelength dependent extinctions were derived from SAGE II $1 \mu \mathrm{m}$ extinction coefficient data. The volcanic aerosol perturbation was included in the heterogeneous chemistry, the heating rates, and the photolysis rates in separate runs, and a combined run in which it was included in the chemistry and radiation. In the low latitudes in the months immediately following the eruption, ozone column depletions of $1-2 \%, 0.5 \%$, and $0.5 \%$ were computed due to the perturbed heating rates, photolysis rates, and heterogeneous chemistry, respectively. The combined effect was to produce a net ozone loss of 2-3\% in the tropics, in good agreement with observations. The computed changes in the ozone mixing ratios showed depleted ozone in the lower stratosphere with enhanced ozone at higher altitudes, in accord with observed profile changes.

In the high latitudes there were computed springtime depletions of $8-10 \%$ in the northern hemisphere and $12-20 \%$ in the southern hemisphere. The model middle and high latitude northern hemisphere losses were larger in magnitude and greater in spatial extent in the spring of 1993 than in 1992, in agreement with observations. This was due to less cancellation in the later year of the decreases due to the heterogeneous chemistry by the increases due to the downwelling produced by the heating rate perturbation.

A low-latitude warming of $2.5 \mathrm{~K}$ was predicted in the middle of 1992 as a result of the perturbation in the heating rates. This is in good agreement with the $2-3 \mathrm{~K}$ tropical warmings observed. High-latitude coolings of $1-2 \mathrm{~K}$ due to the springtime ozone depletions were computed. Computed global average temperature increases of 1-1.5 $\mathrm{K}$ are also in good agreement with observations.

Computed global average ozone losses reached $1 \%$ at the end of 1991 and fell to a low of 3.2\% around September 1992, after which the ozone began recovering. The computed global ozone changes were within $1 \%$ in absolute magnitude of those observed by the TOMS instrument. The sensitivity of the predicted perturbations to changes in the specification of the planetary wave forcing parameters was examined. For the cases studied, the maximum globally averaged column ozone losses ranged from 2 to $4 \%$.

Acknowledgments. We thank L. Thomason for the SAGE II $1 \mu \mathrm{m}$ extinction data, M. Hitchman for the background aerosol climatology of $1 \mu \mathrm{m}$ extinctions, and the Ozone Processing Team at Goddard Space Flight Center for the version 7 TOMS data.

\section{References}

Angell, J. K., Comparison of stratospheric warming following Agung, El Chichon and Pinatubo volcanic eruptions, Geophys. Res. Lett., 20, 715-718, 1993.

Bacmeister, J. T., M. R. Schoeberl, M. E. Summers, J. E. Rosenfield, and $X$. Zhu, Descent of long-lived trace gases in the winter polar vortex, J. Geophys. Res., 100, 11,669-11,684, 1995. 
Bekki, S., and J. A. Pyle, A two-dimensional modeling study of the volcanic eruption of Mount Pinatubo, J. Geophys. Res., 99, 18,861$18,869,1994$.

Brasseur, G., and C. Granier, Mount Pinatubo aerosols, chlorofluorocarbons and ozone depletion, Science, 257, 1239-1242, 1992.

Chandra, S., Changes in stratospheric ozone and temperature due to the eruption of Mt. Pinatubo, Geophys. Res. Lett., 18, 2277-2280, 1991.

Considine, D. B., A. R. Douglass, and C. H. Jackman, Effects of a polar stratospheric cloud parameterization on ozone depletion due to stratospheric aircraft in a two-dimensional model, J. Geophys. Res., 99, 18,879-18,894, 1994.

Crewell, S., D. Cheng, R. L. de Zafra, and C. Trimble, Millimeter wave spectroscopic measurements over the south pole, 1, A study of stratospheric dynamics using $\mathrm{N}_{2} \mathrm{O}$ observations, J. Geophys. Res., 100, 20,839-20,844, 1995.

DeMore, W. B., M. J. Molina, S. P. Sander, D. M. Golden, R. F. Hampson, M. J. Kurylo, C. J. Howard, and A. R. Ravishankara, Chemical kinetics and photochemical data for use in stratospheric modeling, JPL Publ., 87-41, Jet Propul. Lab., Pasadena, Calif., 1987.

Deshler, T., D. J. Hofmann, B. J. Johnson, and W. R. Rozier, Balloonborne measurements of the Pinatubo aerosol size distribution and volatility at Laramie, Wyoming during the summer of 1991 , Geophys. Res. Lett., 19, 199-202, 1992.

Deshler, T., B. J. Johnson, and W. R. Rozier, Balloonborne measurements of Pinatubo aerosol during 1991 and 1992 at $41^{\circ} \mathrm{N}$ : Vertical profiles, size distribution, and volatility, Geophys. Res. Lett., 20, 1435-1438, 1993.

Douglass, A. R., C. H. Jackman, and R. D. Stolarski, Comparison of model results transporting the odd nitrogen family with results transporting separate odd nitrogen species, J. Geophys. Res., 94, 98629872, 1989.

Garcia, R. R., Parameterization of planetary wave breaking in the middle atmosphere, J. Atmos. Sci., 48, 1405-1419, 1991.

Gleason, J. F., et al., Record low global ozone in 1992, Science, 260, $523-526,1993$.

Grant, W. B., et al., Aerosol-associated changes in tropical stratospheric ozone following the eruption of Mount Pinatubo, J. Geophys. Res., 99, 8197-8211, 1994.

Hanson, D. R., and A. R. Ravishankara, Reaction of $\mathrm{ClONO}_{2}$ with HCL on NAT, NAD, and frozen sulfuric acid and hydrolysis of $\mathrm{N}_{2} \mathrm{O}_{5}$ and $\mathrm{ClONO}_{2}$ on frozen sulfuric acid, J. Geophys. Res., 98, 22,93122,936, 1993 .

Hanson, D. R., and A. R. Ravishankara, Reactive uptake of $\mathrm{ClONO}_{2}$ onto sulfuric acid due to reaction with $\mathrm{HCl}$ and $\mathrm{H}_{2} \mathrm{O}$,J. Phys. Chem., 98, 5728-5735, 1994.

Hitchman, M. H., M. McKay, and C. R. Trepte, A climatology of stratospheric aerosol, J. Geophys. Res., 99, 20,689-20,700, 1994.

Hofmann, D. J., Increase in the stratospheric background sulfuric acid aerosol mass in the past 10 years, Science, 248, 996-1000, 1990.

Hofmann, D. J., S. J. Oltmans, J. M. Harris, W. D. Komhyr, J. A. Lathrop, T. DeFoor, and D. Kuniyuki, Ozonesonde measurements at Hilo, Hawaii, following the eruption of Pinatubo, Geophys. Res. Lett., 20, 1555-1558, 1993.

Hofmann, D. J., S. J. Oltmans, W. D. Komhyr, J. M. Harris, J. A. Lathrop, A. O. Langford, T. Deshler, B. J. Johnson, A. Torres, and W. A. Matthews, Ozone loss in the lower stratosphere over the United States in 1992-1993: Evidence for heterogeneous chemistry on the Pinatubo aerosol, Geophys. Res. Lett., 21, 65-68, 1994.

Hollandsworth, S. M., R. D. McPeters, L. E. Flynn, W. Planet, A. J. Miller, and S. Chandra, Ozone trends deduced from combined Nimbus 7 SBUV and NOAA 11 SBUV/2 data, Geophys. Res. Lett., 22, 905-908, 1995.

Jackman, C. H., A. R. Douglass, R. B. Rood, R. D. McPeters, and P. E. Meade, Effect of solar proton events on the middle atmosphere during the past two solar cycles as computed using a twodimensional model, J. Geophys. Res., 95, 7417-7428, 1990.

Joseph, J. H., W. J. Wiscombe, and J. A. Weinman, The deltaEddington approximation for radiative flux transfer, J. Atmos. Sci., 33, 2452-2459, 1976.

Kinne, S., O. B. Toon, and M. J. Prather, Buffering of stratospheric circulation by changing amounts of tropical ozone: A Pinatubo case study, Geophys. Res. Lett., 19, 1927-1930, 1992.

Kinnison, D. E., K. E. Grant, P. S. Connell, D. A. Rotman, and D. J. Wuebbles, The chemical and radiative effects of the Mount Pinatubo eruption, J. Geophys. Res., 99, 25,705-25,731, 1994.
Koike, K., N. B. Jones, W. A. Matthews, P. V. Johnston, R. L. McKenzie, D. Kinnison, and J. Rodriguez, Impact of Pinatubo aerosols on the partitioning between $\mathrm{NO}_{2}$ and $\mathrm{HNO}_{3}$, Geophys. Res. Lett., 21, 597-600, 1994.

Kumer, J. B., J. L. Mergenthaler, and A. E. Roche, CLAES $\mathrm{CH}_{4}, \mathrm{~N}_{2} \mathrm{O}$ and $\mathrm{CCl}_{2} \mathrm{~F}_{2}$ (F12) global data, Geophys. Res. Lett., 20, 1239-1242, 1993.

Labitzke, K., and M. P. McCormick, Stratospheric temperature increases due to Pinatubo aerosols, Geophys. Res. Lett., 19, 207-210, 1992.

McCormick, M. P., and R. E. Veiga, SAGE II measurements of early Pinatubo aerosols, Geophys. Res. Lett., 19, 155-158, 1992.

McGee, T. J., M. Gross, R. Ferrare, W. Heaps, and U. Singh, Raman DIAL measurements of stratospheric ozone in the presence of volcanic aerosols, Geophys. Res. Lett., 20, 955-958, 1993.

McPeters, R. D., D. F. Heath, and P. K. Bhartia, Average ozone profiles for 1979 from the Nimbus 7 SBUV instrument, $J$. Geophys. Res., 89, 5199-5214, 1984.

McPeters, R. D., S. M. Hollandsworth, L. E. Flynn, J. R. Herman, and C. J. Seftor, Long-term ozone trends derived from the 16-year combined Nimbus 7/Meteor 3 TOMS Version 7 record, Geophys. Res. Lett., 23(25), 3699-3702, 1996.

Michelangeli, D. V., et al., El Chichon volcanic aerosols: Input of radiative, thermal, and chemical perturbations, J. Geophys. Res., 94, $18,429-18,443,1989$.

Newell, R. E., et al., The general circulation of the tropical atmosphere, vol. 2, MIT Press, Cambridge, Mass., 1974.

Newman, P. A., M. R. Schoeberl, R. A. Plumb, and J. E. Rosenfield, Mixing rates calculated potential vorticity, J. Geophys. Res., 93, 5221-5240, 1988.

Ogren, J. A., N. C. Ahlquist, A. D. Clarke, and R. J. Charlson, Measurements of the absorption coefficient of stratospheric aerosols, Geophys. Res. Lett., 8, 9-12, 1981.

Palmer, K. F., and D. Williams, App. Opt., 14, 208-219, 1975.

Pitari, G., A numerical study of the possible perturbation of stratospheric dynamics due to Pinatubo aerosols: Implications for tracer transport, J. Atmos. Sci., 50, 2443-2461, 1993.

Pitari, G., and V. Rizi, An estimate of the chemical and radiative perturbation of stratospheric ozone following the eruption of $\mathrm{Mt}$. Pinatubo, J. Atmos. Sci., 50, 3260-3276, 1993.

Platt, C. M. R., and Harshvardhan, Temperature dependence of cirrus extinction: Implications for climate feedback, J. Geophys. Res., 93, 11,051-11,058, 1988.

Pollack, J. B., O. B. Toon, and D. Wiedman, Radiative properties of the background stratospheric aerosols and implications for perturbed conditions, Geophys. Res. Lett., 8, 26-28, 1981.

Prather, M. J., Numerical advection by conservation of second-order moments, J. Geophys. Res., 91, 6671-6681, 1986.

Prather, M. J., and E. E. Remsberg (Ed.), The Atmospheric Effects of Stratospheric Aircraft: Report of the 1992 Models and Measurements Workshop, NASA Ref. Publ. 1292, vols. I-III, 1993.

Randel, W. J., Global atmospheric circulation statistics, 1000-1 mb, NCAR Tech. Note, NCAR/TN-366+STR., 256 pp., Inf. Serv. Off., Natl. Cent. for Atmos. Res., Boulder, Colo., 1992.

Randel, W. J., F. Wu, J. M. Russell III, J. W. Waters, and L. Froidevaux, Ozone and temperature changes in the stratosphere following the eruption of Mount Pinatubo, J. Geophys. Res., 100, 16,753$16,764,1995$

Roche, A. E., et al., Validation of $\mathrm{CH}_{4}$ and $\mathrm{N}_{2} \mathrm{O}$ measurements by the cryogenic limb array etalon spectrometer instrument on UARS, $J$. Geophys. Res., 101, 9679-9710, 1996.

Rodriguez, J. M., M. K. W. Ko, N. D. Sze, C. W. Heisey, G. K. Yue, and M. P. McCormick, Ozone response to enhanced heterogeneous processing after the eruption of Mt. Pinatubo, Geophys. Res. Lett., 21, 209-212, 1994.

Rosenfield, J. E., A simple parameterization of ozone infrared absorption for atmospheric heating rate calculations, J. Geophys. Res., 96, 9065-9074, 1991

Rosenfield, J. E., Radiative effects of polar stratospheric clouds during the Airborne Antarctic Ozone Experiment and the Airborne Arctic Stratospheric Expedition, J. Geophys. Res., 97, 7841-7858, 1992.

Rosenfield, J. E., M. R. Schoeberl, and M. A. Geller, A computation of the stratospheric diabatic circulation using an accurate radiative transfer model, J. Atmos. Sct., 44, 859-876, 1987.

Rosenfield, J. E., P. A. Newman, and M. R. Schoeberl, Computations 
of diabatic descent in the stratospheric polar vortex, J. Geophys. Res., 99, 16,677-16,689, 1994.

Schoeberl, M. R., P. K. Bhartia, E. Hilsenrath, and O. Torres, Tropical ozone loss following the eruption of Mt. Pinatubo, Geophys. Res. Lett., 20, 29-32, 1993.

Schoeberl, M. R., M. Luo, and J. E. Rosenfield, An analysis of the Antarctic Halogen Occultation Experiment trace gas observations, $J$. Geophys. Res., 100, 5159-5172, 1995.

Solomon, S., R. W. Portmann, R. R. Garcia, L. W. Thomason, L. R. Poole, and M. P. McCormick, The role of aerosol variations in anthropogenic ozone depletion at northern midlatitudes, J. Geophys. Res., 101, 6713-6727, 1996.

Strahan, S. E., J. E. Rosenfield, M. Loewenstein, J. R. Podolske, and A. Weaver, Evolution of the 1991-1992 Arctic vortex and comparison with the Geophysical Fluid Dynamics Laboratory SKYHI general circulation model, J. Geophys. Res., 99, 20,713-20,723, 1994.

Strobel, D. F., Parameterization of the atmospheric heating rate from 15 to $120 \mathrm{~km}$ due to $\mathrm{O}_{2}$ and $\mathrm{O}_{3}$ absorption of solar radiation, $J$. Geophys. Res., 83, 6225-6230, 1978.

Tabazadeh, A., and R. P. Turco, A model for heterogeneous chemical processes on the surfaces of ice and nitric acid trihydrate particles, J. Geophys. Res., 98, 12,727-12,740, 1993.

Tie, X. X., G. P. Brasseur, B. Briegleb, and C. Granier, Twodimensional simulation of Pinatubo aerosol and its effect on stratospheric ozone, J. Geophys. Res., 99, 20,545-20,562, 1994.

Toon, O. B., C. P. McKay, T. P. Ackerman, and K. Santhanam, Rapid calculation of radiative heating rates and photodissociation rates in inhomogeneous multiple scattering atmospheres, J. Geophys. Res., 94, 16,287-16,301, 1989.

Trepte, C. R., R. E. Veiga, and M. P. McCormick, The poleward dispersal of Mount Pinatubo volcanic aerosol, J. Geophys. Res., 98, $18,563-18,573,1993$.

World Meteorological Organization (WMO), Scientific Assessment of Ozone Depletion: 1991, WMO Rep. 25, Global Ozone Res. and Monit. Project, Geneva, 1991.

World Meteorological Organization (WMO), Scientific Assessment of Ozone Depletion: 1994, WMO Rep. 37, Global Ozone Res. and Monit. Project, Geneva, 1995.

Young, R. E., H. Houben, and O. B. Toon, Radiatively forced dispersion of the Mt. Pinatubo volcanic cloud and induced temperature perturbations in the stratosphere during the first few months following the eruption, Geophys. Res. Lett., 21, 369-372, 1994.

Zerefos, C. S., K. Tourpali, and A. F. Bais, Further studies on possible volcanic signal to the ozone layer, J. Geophys. Res., 99, 25,74125,746, 1994.

f. T. Bacmeister, Naval Research Laboratory, Code 7641, Washington, D. C. 20375.

D. B. Considine, C. H. Jackman, P. E. Meade, J. E. Rosenfield, and M. R. Schoeberl, NASA Goddard Space Flight Center, Mail Code 916, Greenbelt, MD 20771. (e-mail: rose@euterpe.gsfc.nasa.gov)

(Received June 6, 1996; revised December 3, 1996; accepted December 3, 1996.) 